\title{
A Comparative Study Between Inventory Followed by Shortages and Shortages Followed by Inventory Under Trade-Credit Policy
}

\author{
S. Khanra · Buddhadev Mandal · B. Sarkar
}

Published online: 22 January 2015

(C) Springer India Pvt. Ltd. 2015

\begin{abstract}
This paper deals with a comparison between inventory followed by shortages model and shortages followed by inventory model with variable demand rate. It is assumed that the stock deteriorates over time which follows a two parameter Weibull distribution. Both the models are assumed fixed trade credit period to the retailer from the supplier. The model is solved analytically and the results are illustrated with numerical examples.
\end{abstract}

Keywords Comparative study • Variable demand · Probabilistic deterioration · Permissible delay-in-payments

\section{Introduction}

The basic square root formula for economic order quantity (EOQ) was used in the inventory literature for a pretty long time under the assumption of constant demand. In real market the demand rate of any product is always in a dynamic state. The modification from constant demand to time varying demand was first studied by Silver and Meal [1]. The first analytical model for the classical no-shortage inventory policy with a linear time-dependent demand was developed by Donaldson [2]. Deb and Chaundhuri [3] were the first to incorporate shortages into the inventory lot-sizing problem with a linearly increasing time varying demand.

Dr. Biswajit Sarkar is in leave on lien from Vidyasagar University.

\section{S. Khanra}

Department of Mathematics, Tamralipta Mahavidyalaya, Purba Medinipur, Tamluk 721 636, India

B. Mandal

Department of Applied Mathematics with Oceanology and Computer Programming, Vidyasagar University, Midnapore 721 102, West Bengal, India

B. Sarkar $(\bowtie)$

Department of Industrial \& Management Engineering, Hanyang University, Ansan, Gyeonggi-do 426 791, South Korea

e-mail: bsbiswajitsarkar@gmail.com 
In recent years, inventory problems for deteriorating items have been widely studied after Ghare and Schrader [4]. They developed an inventory model for an exponentially deterioration. Later, Covert and Philip [5] formulated the inventory model with variable deterioration rate with two-parameter Weibull distribution. In recent Sarkar and Sarkar [6,7] improved an inventory model for variable deteriorating items. Philip [8] then developed the inventory model with a three-parameter Weibull distribution rate without shortage. Shah [9] extended (Philip's [8]) model with shortage was allowed. All these models deal with a replenishment policy that allows shortage in all cycles except the last one. Each of the cycles during which shortages permitted starts with replenishment and ends with a shortage. These replenishment system is known as inventory followed by shortage (IFS) policy of replenishment, Goyal et al. [10] derived a new-replenishment policy in which shortages are permissible in every cycle. In this policy, every cycle starts with a shortage until replenishment is made followed by a period of positive inventory. It is known as shortage followed by inventory (SFI) policy. Several researchers started working on inventory models with time varying demand for items which undergo decay or deteriorating items over time. Some models for deteriorating items with trended demand and IFS policy of replenishment are Goswami and Chaudhuri [11] and Hariga [12]. The inventory models with shortage and time varying demand and Weibull distributed deterioration were studied by Ouyang et al. [13]. Using basic algebraic procedure Goyal and Cárdenas-Barrón [14] derived several simple expressions for the total average cost of inventory items with shortages. Sarkar et al. [15] obtained an inventory model with trade-credit policy where deterioration was considered as variable for fixed lifetime products.

In the conventional EOQ model, it was assumed that the customer must pay for the item as soon as it is received. In practice, however the supplier offers the retailer a certain trade credit period for paying the purchasing cost. During this delay period, the retailer can earn revenue by selling items and earning interest. An inventory model with permissible delay in payments was first studied by Goyal [16]. Aggarwal and Jaggi [17] determined an EOQ model with constant deterioration under permissible delay in payments. Sarkar [18], Chung and Cárdenas-Barrón [19] studied two inventory models for deterioration under permissible delay in payments. Pal et al. [20] developed an integrated inventory model under three levels of trade credit policy. Chung and Huang [21] presented a mathematical model on EOQ for constant demand, shortages under permissible delay in payments. Pal et al. [22] investigated an inventory model with price and credit period dependent demand. Mahata [23] developed an EOQ model with considering time dependent linear demand and shortages under permissible delay-in-payments. Singh and Pattnayak [24], Singh and Singh [25] considered two inventory models for both time-varying demand and deterioration under permissible delay in payments. Amutha and Chandrasekaran [26] obtained an inventory model with constant demand, shortages, and time varying deterioration rate under permissible delay in payments. Anand and Bansal [27] developed an EOQ model for both time varying demand and deterioration rate with shortages under permissible delay in payments. Several valuable contributions in this field were studied by Sarkar and Sarkar [28], Sarkar and Saren [29,30], Sana and Chaudhuri [31], Ouyang et al. [32], Sana [33], Khanra et al. [34,35], Das Roy et al. [36], Sarkar [37,38]. Sarkar et al. [39] developed an economic order quantity (EOQ) model for various types of time-dependent demand where delay-in-payments and price discount are permitted by suppliers to retailers. Sarkar and Sarkar [6] formed an inventory model with partial backlogging and time varying deterioration where demand is considered as stock-dependent. Wu et al. [40] described an inventory model for deteriorating items with expiration dates under two-level trade-credit financing. Chung et al. [41] addressed an integrated three layer supply chain system with non-instantaneous receipt and exponentially deteriorating items under two levels of trade-credit policy. Chen et al. [42] obtained retailer's economic order quantity 
while the supplier offers conditionally permissible delay-in-payments link to order quantity. Sarkar et al. [43] produced an integrated inventory model by considering variable lead time, defective units, and delay in payments. Sarkar and Moon [44] developed the relationship between quality improvement, reorder point, and lead time as affected by backorder rate in an imperfect production process. Sarkar et al. [45] considered an economic production quantity (EPQ) model with rework process at a single-stage manufacturing system with planned backorders. Three different inventory models are formulated for three different distribution density functions such as uniform, triangular, and beta. Sarkar et al. [46] discussed an inventory model to improve the process quality and backorder price discount with controllable lead time.

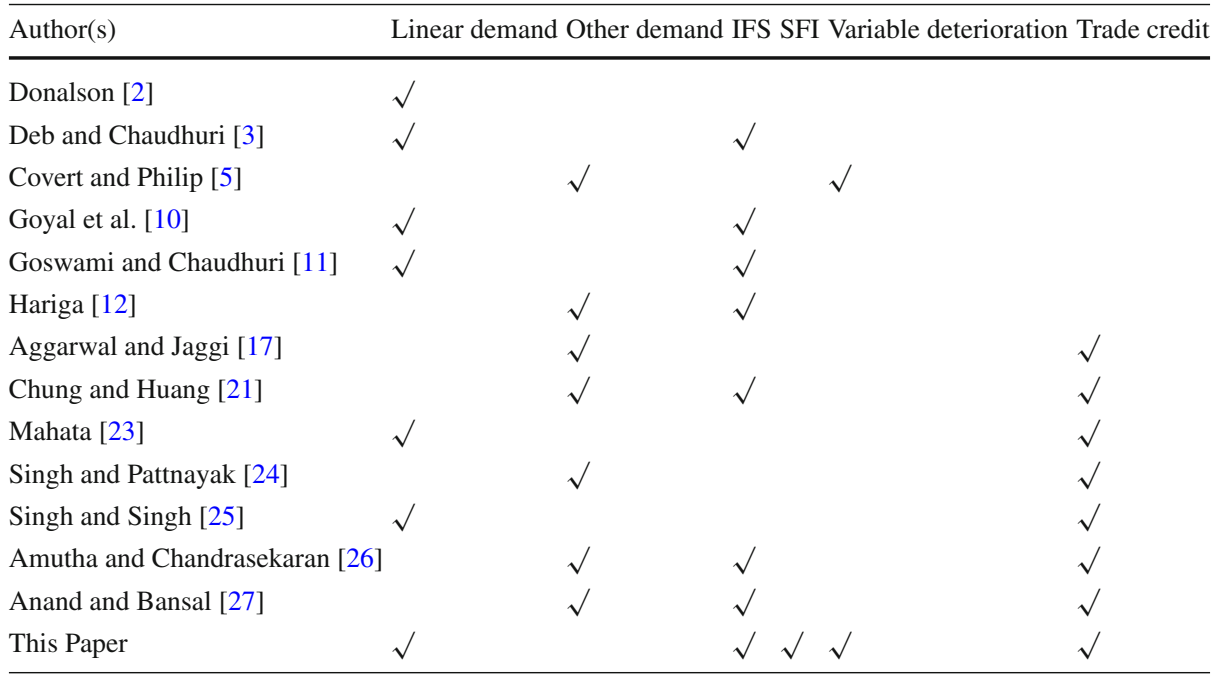

In this paper, a comparison for the effectiveness between inventory followed by shortages (IFS) and shortages followed by inventory (SFI) have been discussed. The models are developed for deterioration items with linear trend in demand, shortages and permissible delay-in-payments. When the demand rate for an item increases or decreases steadily with time, the demand rate is linear function of time and of the form $D(t)=a+b t, a>0, b \neq 0$. However, $b=0$ gives the demand rate as constant. The deterioration rate follows a two parameter Weibull distribution. The model has been developed under two categories and five circumstances as follows: Case 1 IFS policy and the credit period is less than the time of commencement of shortage. Case 2 IFS policy and the credit period is greater than the time of commencement of shortage period but less than cycle length. Case 3 IFS policy and the credit period is greater than the total cycle time for settling the account. Case 4 SFI policy and credit period is greater than commencement of shortages but less than cycle time and Case 5 SFI policy and credit period is greater than cycle time for settling the account. Finally, the model is illustrated with some numerical examples. Also justification of taking the SFI policy rather than IFS policy for managerial point of view is analyzed.

\section{Mathematical Model}

The following assumptions are made to develop this model. 
(i) The inventory system involves only single type of item.

(ii) Replenishment occurs instantaneously.

(iii) The demand rate for the item is represented by a linear and continuous function of time.

(iv) Shortages are considered and completely backlogged.

(v) Delay-in-payments are considered.

(vi) No interest is to be charged after commencement of shortages.

(vii) No interest is to be earned after permissible delay periods.

(viii) The deterioration of products follows a Weibull distribution.

(ix) The planning period is of infinite length.

The following notation is used to develop this model.

\section{Decision variables}

$T \quad$ length of the replenishment cycle (year)

$T_{1} \quad$ time when inventory level comes down to zero (year)

\section{Parameters}

$m \quad$ permissible delay in setting the account (year)

$I(t) \quad$ inventory level at time $\mathrm{t}$

$k \quad$ ordering cost of inventory per order (\$/order)

$h \quad$ unit holding cost per unit time excluding interest charges (\$/unit/unit time)

$c_{2} \quad$ unit cost incurred from the deterioration of one item (\$/unit/unit time)

$s \quad$ unit shortage cost per item (\$/item unit short)

$p \quad$ unit purchase cost per item (\$/item)

$D(t) \quad$ time dependent demand rate (unit/year) $D(t)=a+b t, a>0, b \neq 0$, here $a$ is initial rate of demand, $b$ is the rate with which the demand rate increases.

$Z(t) \quad$ two-parameter Weibull deterioration $Z(t)=\alpha \beta t^{\beta-1}, 0<\alpha<<1, \beta>1$, here $\alpha$ is the scale parameter, $\beta$ is the shape parameter.

$I_{e} \quad$ interest earned per year $(\$ /$ year $)$

$I_{r} \quad$ interest charges per year, $I_{r} \geq I_{e}$ (\$/year)

Shortages Followed by Inventory

The inventory level $I(t)$ at time $t$ generally decreases from $I_{0}$ to meet market's demand and product's deterioration and reaches to zero at $T_{1}$. Thus shortages accumulate over $\left[T_{1}, T\right]$. Hence, the variation of inventory with respect to time can be described by the governing differential equation

$$
\frac{d I(t)}{d t}+Z(t) I(t)=-(a+b t), 0 \leq t \leq T_{1} \text {, with } I(0)=I_{0}
$$

and

$$
\frac{d I(t)}{d t}=-(a+b t), T_{1} \leq t \leq T, \text { with } I\left(T_{1}\right)=0
$$

The deterioration rate

$$
Z(t)=\alpha \beta t^{\beta-1}, 0<\alpha<<1, \beta>1, \text { and } t>0
$$

By virtue of (3), (1) becomes

$$
\frac{d I(t)}{d t}+I(t) \alpha \beta t^{\beta-1}=-(a+b t), 0 \leq t \leq T_{1}
$$


The solution of (4) is

$$
I(t)=\left\{I_{0}-\left(a t+\frac{b}{2} t^{2}+\frac{a \alpha}{\xi_{1}} t^{\xi_{1}}+\frac{b \alpha}{\xi_{2}} t^{\xi_{2}}\right)\right\} \exp \left\{-\alpha t^{\beta}\right\}, 0 \leq t \leq T_{1}
$$

[See Appendix 2 for value of $I_{0}$ ]

The solution of (2) is

$$
I(t)=a\left(T_{1}-t\right)+\frac{b}{2}\left(T_{1}^{2}-t^{2}\right), T_{1} \leq t \leq T
$$

The total deteriorated items are

$$
I_{0}-\int_{0}^{T_{1}}(a+b t) d t=I_{0}-\left\{a T_{1}+\frac{b}{2} T_{1}^{2}\right\}
$$

The shortage cost $(S C)$ over the time interval $\left[T_{1}, T\right]$ is

$$
S C=-s \int_{T_{1}}^{T} I(t) d t=s\left\{\frac{a}{2}\left(T^{2}-T_{1}^{2}\right)+\frac{b}{6}\left(T^{3}-T_{1}^{3}\right)-a T_{1} T-\frac{b}{2} T_{1}^{2} T+a T_{1}^{2}+\frac{b}{2} T_{1}^{3}\right\}
$$

The holding cost $(H C)$ in $\left[0, T_{1}\right]$ is given by

$$
H C=h \int_{0}^{T_{1}} I(t) d t=h\left\{\frac{a}{2} T_{1}^{2}+\frac{b}{3} T_{1}^{3}+\frac{a \sigma}{\xi_{1} \xi_{2}} T_{1}^{\xi_{2}}+\frac{b \sigma}{\xi_{1} \xi_{3}} T_{1}^{\xi_{3}}-\frac{a \alpha^{2}}{\xi_{1} \xi_{5}} T_{1}^{\xi_{5}}-\frac{b \alpha^{2}}{\xi_{1} \xi_{6}} T_{1}^{\xi_{6}}\right\}
$$

[See Appendix 2 for all values of $\xi_{i}, i=1,2, \ldots \ldots 6$ ]

The total deterioration cost $(D C)$ is given by

$$
D C=c_{2}\left\{I_{0}-\left(a T_{1}+\frac{b}{2} T_{1}^{2}\right)\right\}
$$

The permissible delay period $m$ is settled by the whole-seller or distributor to the retailer or customer. Thus, three models can be developed depending on different values of $m, T_{1}$, and $T$.

Case 1 Let $m \leq T_{1}<T$ (Fig. 1).

As the length of the period with positive stock is larger than credit period, the buyer can used sales revenue to earn interest at an annual rate $I_{e}$ in $[0, m]$.

The interest earned $E_{1}$ is given by

$$
E_{1}=p I_{e} \int_{0}^{m} t D(t) d t=p I_{e}\left(\frac{a}{2} m^{2}+\frac{b}{3} m^{3}\right)
$$


Case 1. Let $m \leq T_{1}<T$.

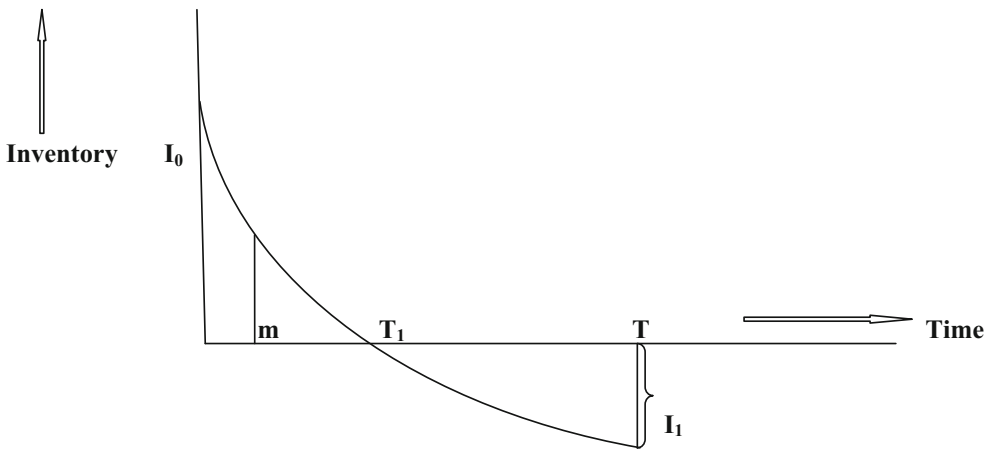

Fig. 1 Inventory versus time for Model $\mathrm{I} m \leq T_{1}<T$

Beyond the credit period, the unsold stock is supposed to be financed with an annual rate $I_{r}$.

$$
\begin{aligned}
L_{1}= & p I_{r} \int_{m}^{T_{1}} I(t) d t \\
= & p I_{r}\left\{I_{0}\left(T_{1}-m\right)-\frac{a}{2}\left(T_{1}^{2}-m^{2}\right)-\frac{b}{6}\left(T_{1}^{3}-m^{3}\right)-\frac{I_{0} \alpha}{\xi_{1}}\left(T_{1}^{\xi_{1}}-m^{\xi_{1}}\right)\right. \\
& \left.+\frac{a \sigma}{\xi_{1} \xi_{2}}\left(T_{1}^{\xi_{2}}-m^{\xi_{2}}\right)+\frac{b \sigma}{2 \xi_{2} \xi_{3}}\left(T_{1}^{\xi_{3}}-m^{\xi_{3}}\right)+\frac{a \alpha^{2}}{\xi_{1} \xi_{5}}\left(T_{1}^{\xi_{5}}-m^{\xi_{5}}\right)+\frac{b \alpha^{2}}{\xi_{2} \xi_{6}}\left(T_{1}^{\xi_{6}}-m^{\xi_{6}}\right)\right\}
\end{aligned}
$$

Therefore, the total average cost per unit time is given by

$$
\begin{aligned}
Z_{1}\left(T_{1}, T\right)= & \frac{1}{T}\left[k+D C+H C+S C+L_{1}-E_{1}\right] \\
= & \frac{1}{T}\left[k+c_{2}\left(I_{0}-a T_{1}+\frac{b}{2} T_{1}^{2}\right)+h\left\{\frac{a}{2} T_{1}^{2}+\frac{b}{3} T_{1}^{3}+\frac{a \sigma}{\xi_{1} \xi_{2}} T_{1}^{\xi_{2}}+\frac{b \sigma}{\xi_{1} \xi_{3}} T_{1}^{\xi_{3}}\right.\right. \\
& \left.-\frac{a \alpha^{2}}{\xi_{1} \xi_{5}} T_{1}^{\xi_{5}}-\frac{b \alpha^{2}}{\xi_{2} \xi_{6}} T_{1}^{\xi_{6}}\right\}+s \eta+p I_{r}\left\{I_{0}\left(T_{1}-m\right)-\frac{a}{2}\left(T_{1}^{2}-m^{2}\right)\right. \\
& -\frac{b}{6}\left(T_{1}^{3}-m^{3}\right)-\frac{I_{0} \alpha}{\xi_{1}}\left(T_{1}^{\xi_{1}}-m^{\xi_{1}}\right)+\frac{a \sigma}{\xi_{1} \xi_{2}}\left(T_{1}^{\xi_{2}}-m^{\xi_{2}}\right)+\frac{b \sigma}{2 \xi_{2} \xi_{3}}\left(T_{1}^{\xi_{3}}-m^{\xi_{3}}\right) \\
& \left.\left.+\frac{a \alpha^{2}}{\xi_{1} \xi_{5}}\left(T_{1}^{\xi_{5}}-m^{\xi_{5}}\right)+\frac{b \alpha^{2}}{\xi_{2} \xi_{6}}\left(T_{1}^{\xi_{6}}-m^{\xi_{6}}\right)\right\}-p I_{e}\left(\frac{a}{2} m^{2}+\frac{b}{3} m^{3}\right)\right]
\end{aligned}
$$

Our aim is to obtain the minimum average cost per unit time.

We now take the following theorem which was established by [35].

Theorem 1 If a function $V\left(T_{1}, T\right)=\frac{1}{T} G\left(T_{1}, T\right)$ where $G\left(T_{1}, T\right)$ admits continuous partial derivatives of second order then $V\left(T_{1}, T\right)$ is minimum at $T_{1}=T_{1}^{*}, T=T^{*}$, if all principal minors are positive definite i.e., if

$$
\frac{\partial^{2} G\left(T_{1}, T\right)}{\partial T_{1}^{2}}>0 \text { and }\left|\begin{array}{ll}
\frac{\partial^{2} G\left(T_{1}, T\right)}{\partial T_{1}^{2}} & \frac{\partial^{2} G\left(T_{1}, T\right)}{\partial T_{1} \partial T} \\
\frac{\partial^{2} G\left(T_{1}, T\right)}{\partial T_{1} \partial T} & \frac{\partial^{2} G\left(T_{1}, T\right)}{\partial T^{2}}
\end{array}\right|>0
$$

[See Appendix 1 for proof.] 
Case 2. Let $T_{1}<m<T$.

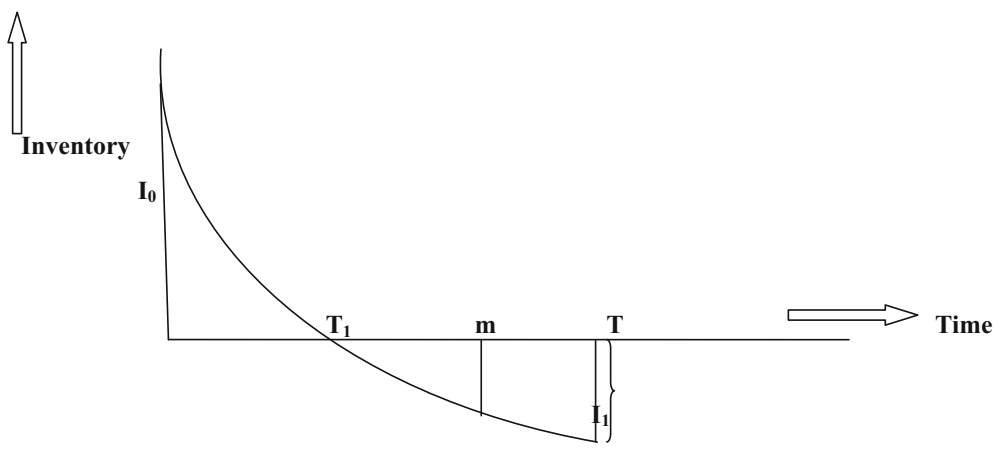

Fig. 2 Inventory versus time for Model II $T_{1}<m<T$

Lemma $1 Z_{1}\left(T_{1}, T\right)$ has the minimum value for those values of $T$ and $T_{1}$ which satisfy following equations

$$
\begin{aligned}
& \text { (i) } c_{2} \lambda_{1}+h\left(a T_{1}+b T_{1}^{2}\right)+h\left\{\frac{a \sigma}{\xi_{1}} T_{1}^{\xi_{1}}+\frac{b \sigma}{\xi_{1}} T_{1}^{\xi_{2}}-\frac{a \alpha^{2}}{\xi_{1}} T_{1}^{\xi_{4}}-\frac{b \alpha^{2}}{\xi_{2}} T_{1}^{\xi_{5}}\right\} \\
& +s \lambda_{2}+p \lambda_{3} I_{r}\left\{\left(T_{1}-m\right)-\frac{\alpha}{\xi_{1}}\left(T_{1}^{\xi_{1}}-m^{\xi_{1}}\right)+I_{0}\left(1-\alpha T_{1}^{\beta}\right)-\tau\right\}=0 \\
& \text { (ii) } k+c_{2} \lambda_{4}+h \lambda_{5}+s \eta+p I_{r} \lambda_{6}-p I_{e} \lambda_{7}-T s \lambda_{8}=0
\end{aligned}
$$

provided the following conditions are satisfied

$$
\begin{aligned}
& \text { (iii) } c_{2} \lambda_{9}+h \lambda_{10}+h\left\{\frac{b \sigma \xi_{2}}{\xi_{1}} T_{1}^{\xi_{1}}-\frac{a \alpha^{2} \xi_{4}}{\xi_{1}} T_{1}^{2 \beta}-\frac{b \alpha^{2} \xi_{5}}{\xi_{2}} T_{1}^{\xi_{4}}\right\}+s \lambda_{11} \\
& +p I_{r}\left(b+\lambda_{4}\right)\left\{\left(T_{1}-m\right)-\frac{\alpha}{\xi_{1}}\left(T_{1}^{\xi_{1}}-m^{\xi_{1}}\right)\right\}>p \alpha I_{r} \lambda_{3} T_{1}^{\beta}+I_{0} \sigma T_{1}^{\beta-1}+\left(a+b T_{1}\right)
\end{aligned}
$$

and

$$
\begin{aligned}
& \text { (iv) }\left[c_{2} \lambda_{4}+h \lambda_{5}+h\left\{\frac{b \sigma \xi_{2}}{\xi_{1}} T_{1}^{\xi_{1}}-\frac{a \alpha^{2} \xi_{4}}{\xi_{1}} T_{1}^{2 \beta}-\frac{b \alpha^{2} \xi_{5}}{\xi_{2}} T_{1}^{\xi_{4}}\right\}+s \lambda_{6}+p I_{r}\left(b+\lambda_{4}\right)\right. \\
& \left.\left\{\left(T_{1}-m\right)-\frac{\alpha}{\xi_{1}}\left(T_{1}^{\xi_{1}}-m^{\xi_{1}}\right)\right\}-p \alpha I_{r} \lambda_{3} T_{1}^{\beta}-I_{0} \sigma T_{1}^{\beta-1}-\left(a+b T_{1}\right)\right](a+b T) \\
& >s\left(a+b T_{1}\right)^{2}
\end{aligned}
$$

[See Appendix 2 for all values]

[See Appendix 3 for proof.]

Case 2 Let $T_{1}<m<T$ (Fig. 2).

In this case, the buyer pays no interest but earns interest at an annual rate $I_{e}$. 
During the period $[0, m]$ the interest earned $E_{2}$ is given by

$$
\begin{aligned}
E_{2} & =p I_{e} \int_{0}^{T_{1}} t D(t) d t+\left(m-T_{1}\right) p I_{e} \int_{0}^{T_{1}} D(t) d t \\
& =p I_{e}\left(\frac{a}{2} T_{1}^{2}+\frac{b}{3} T_{1}^{3}\right)+p I_{e}\left(m-T_{1}\right)\left(a T_{1}+\frac{b}{2} T_{1}^{2}\right) \\
& =p m I_{e}\left(a T_{1}+\frac{b}{2} T_{1}^{2}\right)-p I_{e}\left(\frac{a}{2} T_{1}^{2}+\frac{b}{6} T_{1}^{3}\right)
\end{aligned}
$$

Therefore the total average cost per unit time is

$$
\begin{aligned}
Z_{2}\left(T_{1}, T\right)= & \frac{1}{T}\left[k+D C+H C+S C-E_{2}\right] \\
= & \frac{1}{T}\left[k+c_{2} \lambda_{4}+h\left\{\frac{a}{2} T_{1}^{2}+\frac{b}{3} T_{1}^{3}+\frac{a \sigma}{\xi_{1} \xi_{2}} T_{1}^{\xi_{2}}+\frac{b \sigma}{\xi_{1} \xi_{3}} T_{1}^{\xi_{3}}-\frac{a \alpha^{2}}{\xi_{1} \xi_{5}} T_{1}^{\xi_{5}}\right.\right. \\
& \left.\left.-\frac{b \alpha^{2}}{\xi_{2} \xi_{6}} T_{1}^{\xi_{6}}\right\}+s \eta-p m I_{e} \tau+p I_{e}\left(\frac{a}{2} T_{1}^{2}+\frac{b}{6} T_{1}^{3}\right)\right]
\end{aligned}
$$

We now minimize $Z_{2}\left(T_{1}, T\right)$.

Lemma $2 Z_{2}\left(T_{1}, T\right)$ has the minimum value for those values of $T$ and $T_{1}$ which satisfy the following equations

$$
\begin{aligned}
& \text { (i) } c_{2} \lambda_{1}+h\left\{\frac{a}{2} T_{1}^{2}+\frac{b}{3} T_{1}^{3}+\frac{a \sigma}{\xi_{1} \xi_{2}} T_{1}^{\xi_{2}}+\frac{b \sigma}{\xi_{1} \xi_{3}} T_{1}^{\xi_{3}}-\frac{a \alpha^{2}}{\xi_{1} \xi_{5}} T_{1}^{\xi_{5}}-\frac{b \alpha^{2}}{\xi_{2} \xi_{6}} T_{1}^{\xi_{6}}\right\} \\
& \quad+s \lambda_{2}+p I_{e} \tau-p m I_{e}\left(a+b T_{1}\right)=0 \\
& \text { (ii) } k+c_{2} \lambda_{4}+h \lambda_{5}+s \eta-p I_{e} \lambda_{12}-p m I_{e} \tau-T s \lambda_{8}=0
\end{aligned}
$$

provided the following conditions are satisfied

(iii) $c_{2} \lambda_{4}+h \lambda_{5}+h\left\{\frac{b \sigma \xi_{2}}{\xi_{1}} T_{1}^{\xi_{1}}-\frac{a \alpha^{2} \xi_{4}}{\xi_{1}} T_{1}^{2 \beta}-\frac{b \alpha^{2} \xi_{5}}{\xi_{2}} T_{1}^{\xi_{4}}\right\}+s \lambda_{6}+p I_{e}\left(a+b T_{1}\right)$

$>\operatorname{pbmI}_{e}$

and

$$
\begin{aligned}
\text { (iv) } & {\left[c_{2} \lambda_{4}+h \lambda_{5}+h\left\{\frac{b \sigma \xi_{2}}{\xi_{1}} T_{1}^{\xi_{1}}-\frac{a \alpha^{2} \xi_{4}}{\xi_{1}} T_{1}^{2 \beta}-\frac{b \alpha^{2} \xi_{5}}{\xi_{2}} T_{1}^{\xi_{4}}\right\}+s \lambda_{6}+p I_{e}\left(a+b T_{1}\right)\right.} \\
- & \left.p b m I_{e}\right](a+b T)>s\left(a+b T_{1}\right)^{2}
\end{aligned}
$$

[See Appendix 4 for proof.]

\section{Case 3 Let $m \geq T$ (Fig. 3).}

In this case, the customer earns interest on the sales revenue upto the permissible delay period and does not pay interest during the period for the time period $[0, T]$ is

$$
p I_{e} \int_{0}^{T_{1}} t D(t) d t=p I_{e}\left(\frac{a}{2} T_{1}^{2}+\frac{b}{3} T_{1}^{3}\right)
$$


Case 3. Let $m \geq T$.

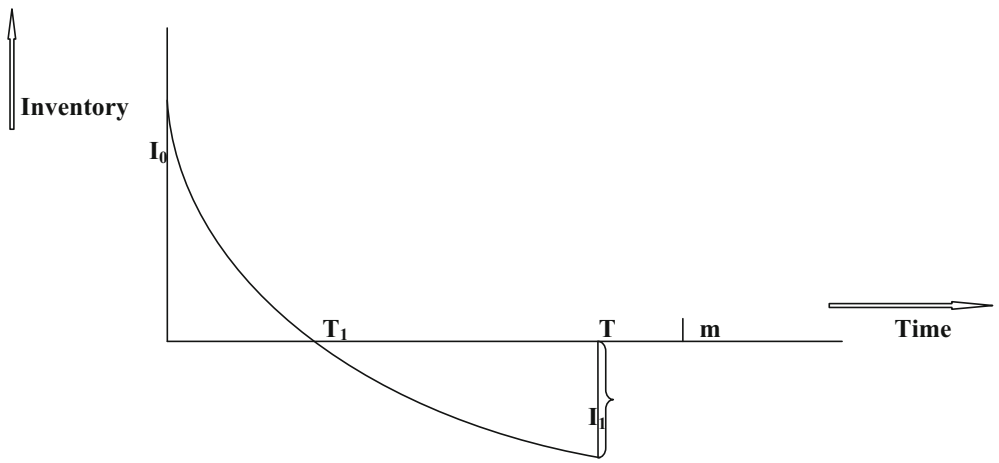

Fig. 3 Inventory versus time for Model III $m \geq T$

Interest earned for the permissible delay period $\left[T_{1}, m\right]$ is

$$
\left(m-T_{1}\right) p I_{e} \int_{0}^{T_{1}} D(t) d t=p I_{e}\left(m-T_{1}\right)\left(a T_{1}+\frac{b}{2} T_{1}^{2}\right)
$$

Therefore the total interest earned during the cycle is

$$
E_{3}=p I_{e}\left(\frac{a}{2} T_{1}^{2}+\frac{b}{3} T_{1}^{3}\right)+p I_{e}\left(m-T_{1}\right)\left(a T_{1}+\frac{b}{2} T_{1}^{2}\right)=p m I_{e} \tau-p I_{e} \lambda_{12}
$$

Hence the total average cost per unit time is

$$
\begin{aligned}
Z_{3}\left(T_{1}, T\right)= & \frac{1}{T}\left[k+D C+H C+S C-E_{3}\right] \\
= & \frac{1}{T}\left[k+c_{2} \lambda_{4}+h\left\{\frac{a}{2} T_{1}^{2}+\frac{b}{3} T_{1}^{3}+\frac{a \sigma}{\xi_{1} \xi_{2}} T_{1}^{\xi_{2}}+\frac{b \sigma}{\xi_{1} \xi_{3}} T_{1}^{\xi_{3}}-\frac{a \alpha^{2}}{\xi_{1} \xi_{5}} T_{1}^{\xi_{5}}\right.\right. \\
& \left.\left.-\frac{b \alpha^{2}}{\xi_{2} \xi_{6}} T_{1}^{\xi_{6}}\right\}+s \eta+p I_{e} \lambda_{12}-p m I_{e} \tau\right]
\end{aligned}
$$

We minimize $Z_{3}\left(T_{1}, T\right)$.

Lemma $3 Z_{3}\left(T_{1}, T\right)$ has the minimum value for those values of $T$ and $T_{1}$ which satisfy the following equations

$$
\begin{aligned}
& \text { (i) } c_{2} \lambda_{1}+h\left\{\frac{a}{2} T_{1}^{2}+\frac{b}{3} T_{1}^{3}+\frac{a \sigma}{\xi_{1} \xi_{2}} T_{1}^{\xi_{2}}+\frac{b \sigma}{\xi_{1} \xi_{3}} T_{1}^{\xi_{3}}-\frac{a \alpha^{2}}{\xi_{1} \xi_{5}} T_{1}^{\xi_{5}}-\frac{b \alpha^{2}}{\xi_{2} \xi_{6}} T_{1}^{\xi_{6}}\right\}+s \lambda_{2}+p I_{e} \tau \\
& -p m I_{e}\left(a+b T_{1}\right)=0 \\
& \text { (ii) } k+c_{2} \lambda_{4}+h \lambda_{5}+s \eta-p I_{e} \lambda_{12}-p m I_{e} \tau-T s \lambda_{8}=0
\end{aligned}
$$

provided they satisfy the following conditions

$$
\begin{aligned}
& \text { (iii) } c_{2} \lambda_{4}+h \lambda_{5}+h\left\{\frac{b \sigma \xi_{2}}{\xi_{1}} T_{1}^{\xi_{1}}-\frac{a \alpha^{2} \xi_{4}}{\xi_{1}} T_{1}^{2 \beta}-\frac{b \alpha^{2} \xi_{5}}{\xi_{2}} T_{1}^{\xi_{4}}\right\}+s \lambda_{6}+p I_{e}\left(a+b T_{1}\right) \\
& >p b m I_{e}
\end{aligned}
$$


and

$$
\begin{aligned}
\text { (iv) }\left[c_{2} \lambda_{4}+h \lambda_{5}+h\left\{\frac{b \sigma \xi_{2}}{\xi_{1}} T_{1}^{\xi_{1}}-\frac{a \alpha^{2} \xi_{4}}{\xi_{1}} T_{1}^{2 \beta}-\frac{b \alpha^{2} \xi_{5}}{\xi_{2}} T_{1}^{\xi_{4}}\right\}+s \lambda_{6}+p I_{e}\left(a+b T_{1}\right)\right. \\
\left.-p b m I_{e}\right](a+b T)>s\left(a+b T_{1}\right)^{2}
\end{aligned}
$$

[See Appendix 5 for proof.]

Inventory Followed by Shortages

The initial stock is zero. Shortages begin to accumulate over $\left[0, T_{1}\right]$. At $T_{1}$, the replenishment takes place. The inventory gradually decreases during $\left[T_{1}, T\right]$ and after adjusting existing demand and deterioration it becomes zero at the end of cycle time $T$. The instantaneous state of the inventory level $I(t)$ at any time $t$ is governed by the differential equations

$$
\frac{d I(t)}{d t}=-(a+b t), 0 \leq t \leq T_{1} \text {, with } I(0)=0 \text { and } I\left(T_{1}\right)=I_{1}
$$

and

$$
\frac{d I(t)}{d t}+I(t) Z(t)=-(a+b t), T_{1}<t<T, \text { with } I(T)=0
$$

The solution of (16) is

$$
I(t)=-\left(a t+\frac{b}{2} t^{2}\right), 0 \leq t \leq T_{1}
$$

The deterioration rate $Z(t)$ follows a two-parameter Weibull distribution as

$$
Z(t)=\alpha \beta t^{\beta-1}, \alpha>0, \beta>0, \text { and } t>0
$$

By virtue of (20), (18) becomes

$$
\frac{d I(t)}{d t}+I(t) \alpha \beta t^{\beta-1}=-(a+b t), T_{1} \leq t<T
$$

Hence, the solution of (5) is

$$
\begin{aligned}
I(t)= & \left\{a(T-t)+\frac{b}{2}\left(T^{2}-t^{2}\right)+\frac{a \alpha}{\xi_{1}}\left(T^{\xi_{1}}-t^{\xi_{1}}\right)+\frac{b \alpha}{\xi_{2}}\left(T^{\xi_{2}}-t^{\xi_{2}}\right)\right\} \\
& \exp \left\{-\alpha t^{\beta}\right\}, T_{1} \leq t<T
\end{aligned}
$$

[See Appendix 2 for value of $I_{1}$ ]

The total deteriorated items are

$$
I_{1}-\int_{T_{1}}^{T}(a+b t) d t=I_{1}-\left\{a T_{1}+\frac{b}{2} T_{1}^{2}\right\}
$$

The shortage cost $(S C)$ over the time interval $\left[0, T_{1}\right]$ is

$$
S C=-s \int_{0}^{T_{1}} I(t) d t=s\left\{\frac{a}{2} T_{1}^{2}+\frac{b}{6} T_{1}^{3}\right\}
$$


Case 4. $T_{1}<m<T$.

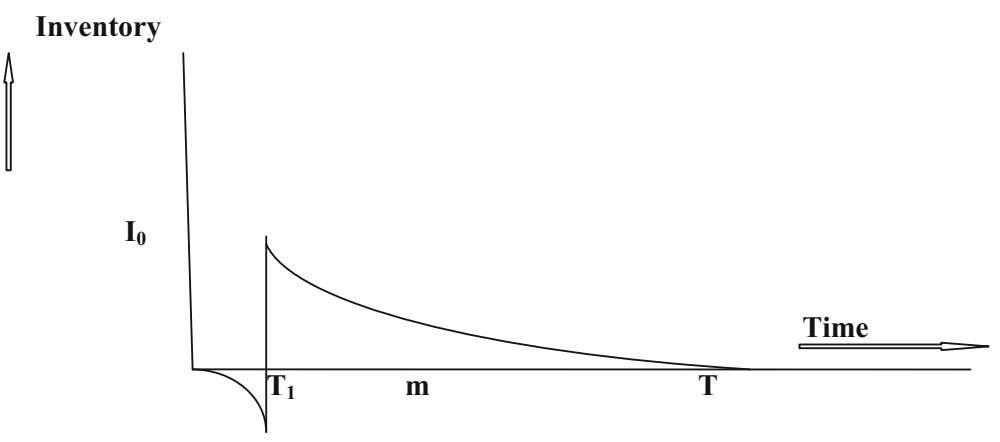

Fig. 4 Inventory versus time for Model IV $T_{1}<m<T$

The holding cost $(H C)$ in $\left[0, T_{1}\right]$ is given by

$$
\begin{aligned}
H C= & h \int_{T_{1}}^{T} I(t) d t=h\left\{\frac{a \alpha}{\xi_{2}}\left(T^{\xi_{2}}-T_{1}^{\xi_{2}}\right)+\frac{b \alpha}{\xi_{3}}\left(T^{\xi_{3}}-T_{1}^{\xi_{3}}\right)+\frac{a \alpha^{2}}{\xi_{1} \xi_{5}}\left(T^{\xi_{5}}-T_{1}^{\xi_{5}}\right)\right. \\
& \left.+\frac{b \alpha^{2}}{\xi_{2} \xi_{6}}\left(T^{\xi_{6}}-T_{1}^{\xi_{6}}\right)\right\}-h\left\{\frac{a}{2}\left(T^{2}-T_{1}^{2}\right)+\frac{b}{6}\left(T^{3}-T_{1}^{3}\right)+\frac{a \alpha}{\xi_{1} \xi_{2}}\left(T^{\xi_{2}}-T_{1}^{\xi_{2}}\right)\right. \\
& \left.+\frac{b \alpha}{\xi_{2} \xi_{3}}\left(T^{\xi_{3}}-T_{1}^{\xi_{3}}\right)\right\}-\frac{h \alpha \mu_{1}}{\beta}\left(T^{\zeta}-T_{1}^{\zeta}\right)
\end{aligned}
$$

The total deterioration cost $(D C)$ is given by

$$
\begin{aligned}
D C= & c_{2}\left\{I_{1}-\left(a T_{1}+\frac{b}{2} T_{1}^{2}\right)\right\}=\left(\frac{a \alpha}{\xi_{1}} T^{\xi_{1}}+\frac{b \alpha}{\xi_{2}} T^{\xi_{2}}\right) \\
& \times\left\{\left(1-\alpha T_{1}^{\beta}\right)-\left(\frac{a \alpha^{2}}{\xi_{1}} T_{1}^{\xi_{4}}+\frac{b \alpha^{2}}{\xi_{2}} T_{1}^{\xi_{5}}\right)\right\}-\alpha T_{1}^{\beta} \lambda_{8}
\end{aligned}
$$

Case $4 T_{1}<m<T$ (Fig. 4).

In this case, buyer pays no interest but earns interest at an annual rate $I_{e}$ during the period $\left[T_{1}, m\right]$. Interest earned $E_{4}$ is given by

$$
E_{4}=p I_{e} \int_{T_{1}}^{m} t D(t) d t=p I_{e}\left\{\frac{a}{2}\left(m^{2}-T_{1}^{2}\right)+\frac{b}{3}\left(m^{3}-T_{1}^{3}\right)\right\}
$$

Beyond the credit period, the interest payable $L_{4}$ is given by

$$
\begin{aligned}
L_{4}= & p I_{r} \int_{m}^{T} I(t) d t=p I_{r}(T-m)\left\{a T+\frac{b}{2} T^{2}+\frac{a \alpha}{\xi_{1}} T^{\xi_{1}}+\frac{b \alpha}{\xi_{2}} T^{\xi_{2}}\right\} \\
& -p I_{r}\left\{\frac{a}{2}\left(T^{2}-m^{2}\right)+\frac{b}{6}\left(T^{3}-m^{3}\right)+\frac{a \alpha}{\xi_{1} \xi_{2}}\left(T^{\xi_{2}}-m^{\xi_{2}}\right)+\frac{b \alpha}{\xi_{2} \xi_{3}}\left(T^{\xi_{3}}-m^{\xi_{3}}\right)\right\}
\end{aligned}
$$

Therefore, the total average cost per unit time is given by 


$$
\begin{aligned}
Z_{4}\left(T_{1}, T\right)=\frac{1}{T}\left[k+D C+H C+S C+L_{4}-E_{4}\right] \\
=\frac{1}{T}\left[k+c_{2}\left(1-\alpha T_{1}^{\beta}\right) \mu_{2}-c_{2} \mu_{2}-c_{2} \alpha T_{1}^{\beta} \lambda_{8}+c_{2}\left\{\frac{a \alpha^{2}}{\xi_{1}} T_{1}^{\xi_{4}}+\frac{b \alpha^{2}}{\xi_{2}} T_{1}^{\xi_{5}}\right\}\right. \\
+h\left\{\frac{a \alpha}{\xi_{2}}\left(T^{\xi_{2}}-T_{1}^{\xi_{2}}\right)+\frac{b \alpha}{\xi_{3}}\left(T^{\xi_{3}}-T_{1}^{\xi_{3}}\right)+\frac{a \alpha^{2}}{\xi_{1} \xi_{5}}\left(T^{\xi_{5}}-T_{1}^{\xi_{5}}\right)+\frac{b \alpha^{2}}{\xi_{2} \xi_{6}}\left(T^{\xi_{6}}-T_{1}^{\xi_{6}}\right)\right\} \\
-h\left\{\frac{a}{2}\left(T^{2}-T_{1}^{2}\right)+\frac{b}{6}\left(T^{3}-T_{1}^{3}\right)+\frac{a \alpha}{\xi_{1} \xi_{2}}\left(T^{\xi_{2}}-T_{1}^{\xi_{2}}\right)+\frac{b \alpha}{\xi_{2} \xi_{3}}\left(T^{\xi_{3}}-T_{1}^{\xi_{3}}\right)\right\} \\
-\frac{h \alpha \mu_{1}}{\beta}\left(T^{\zeta}-T_{1}^{\zeta}\right)+s \lambda_{12}+p I_{r} \mu_{1}-p I_{e}\left\{\frac{a}{2}\left(m^{2}-T_{1}^{2}\right)+\frac{b}{3}\left(m^{3}-T_{1}^{3}\right)\right\} \\
\left.\quad-p I_{r}\left\{\frac{a}{2}\left(T^{2}-m^{2}\right)+\frac{b}{6}\left(T^{3}-m^{3}\right)+\frac{a \alpha}{\xi_{1} \xi_{2}}\left(T^{\xi_{2}}-m^{\xi_{2}}\right)+\frac{b \alpha}{\xi_{2} \xi_{3}}\left(T^{\xi_{3}}-m^{\xi_{3}}\right)\right\}\right]
\end{aligned}
$$

Now we have minimize $Z_{4}\left(T_{1}, T\right)$. For this purpose we consider the following lemma.

Lemma $4 Z_{4}\left(T_{1}, T\right)$ has the minimum value for those values of $T$ and $T_{1}$ which satisfy the following equations

(i) $c_{2} \mu_{3}-c_{2} \sigma T_{1}^{\zeta}\left(\lambda_{8}+\mu_{2}\right)-c_{2} \mu_{4}+c_{2} \alpha T_{1}^{\beta}\left(a+b T_{1}\right)-h \mu_{5}$

$+h\left(\tau+\mu_{6}\right)+\frac{h \alpha \zeta_{1}}{\beta} \mu_{1} T_{1}^{\zeta_{2}}+s\left(a+b T_{1}\right)+p I_{e}\left(a T_{1}+b T_{1}^{2}\right)=0$

(ii) $M-T c_{2} \mu_{5}\left(1-\alpha T_{1}^{\beta}\right)+T c_{2} \alpha T_{1}^{\beta}(a+b T)-h \mu_{7} T+T \mu_{1}\left\{p I_{r}+h+\frac{h \alpha \zeta_{1}}{\beta} T^{\zeta_{2}}\right\}$

$$
-T \mu_{8}\left\{p I_{r}-\frac{h \alpha}{\beta}\left(T^{\zeta_{1}}-T_{1}^{\zeta_{1}}\right)\right\}=0
$$

provided they satisfy the following sufficient conditions

$$
\begin{aligned}
& \text { (iii) } c_{2} \mu_{9}-c_{2} \alpha \beta \zeta_{1} T_{1}^{\zeta_{2}}\left(\lambda_{8}+\mu_{2}\right)+2 c_{2} \sigma T_{1}^{\zeta_{1}}\left(a+b T_{1}\right)+c_{2} b \alpha T_{1}^{\beta}+h \mu_{10} \\
& +\frac{h \alpha \zeta_{1} \zeta_{2}}{\beta} \mu_{1} T_{1}^{\zeta_{3}}+s b+p I_{e}\left(a+2 b T_{1}\right)>h \mu_{11}+c_{2} \lambda_{9} \\
& \text { (iv) }\left[c_{2} \mu_{9}+s b+p I_{e}\left(a+2 b T_{1}\right)-c_{2} \alpha \beta \zeta_{1} T_{1}^{\zeta_{2}} \mu_{1}+2 c_{2} \sigma T_{1}^{\zeta_{1}}\left(a+b T_{1}\right)+c_{2} b \alpha T_{1}^{\beta}\right. \\
& \left.-c_{2} \lambda_{9}+h \mu_{10}-h \mu_{11}+\frac{h \alpha \zeta_{1} \zeta_{2}}{\beta} \mu_{1} T_{1}^{\zeta_{3}}\right]\left[c_{2} \mu_{12}\left(1-\alpha T_{1}^{\beta}\right)-c_{2} \alpha b T_{1}^{\beta}\right. \\
& +\left(b+\mu_{12}\right)\left\{p I_{r}-\frac{h \alpha}{\beta}\left(T^{\zeta_{1}}-T_{1}^{\zeta_{1}}\right)\right\}+h \mu_{13}-\left\{p I_{r}+h+\frac{2 h \alpha \zeta_{1}}{\beta} T^{\zeta_{2}}\right\} \\
& \left.\mu_{8}-\frac{h \alpha \zeta_{1} \zeta_{2}}{\beta} \mu_{1} T^{\zeta_{3}}\right]>\left[c_{2} \sigma \mu_{12} T_{1}^{\zeta_{1}}+c_{2} b \sigma T_{1}^{\zeta_{1}}-\frac{h \alpha \zeta_{1}}{\beta}\left(b+\mu_{12}\right) T_{1}^{\zeta_{2}}\right]^{2}
\end{aligned}
$$

[See Appendix 6 for proof.]

Case $5 m \geq T$ (Fig. 5).

In this case the customer earns interest on the sales revenue upto the permissible delay period and no interest to payable during the period for the time period $[0, T]$ is 


\section{Case 5. $m \geq T$.}

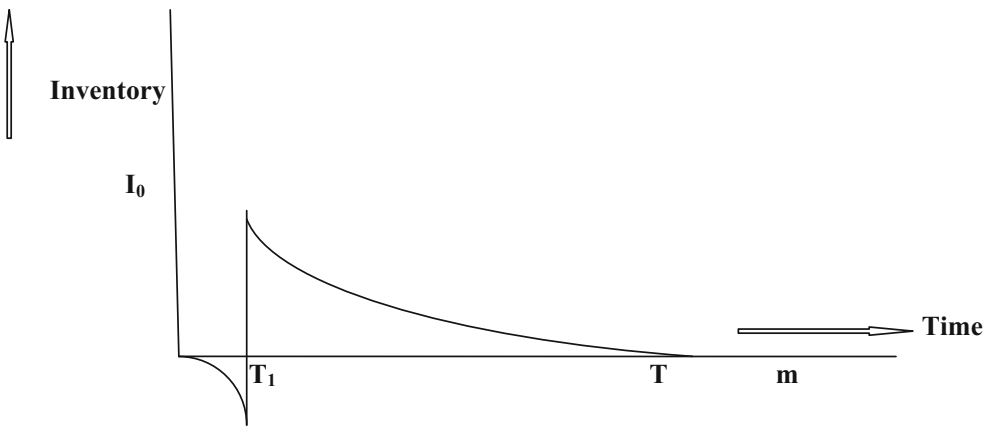

Fig. 5 Inventory versus time for Model $\mathrm{V} T_{1}<T \leq m$

$$
\begin{aligned}
E_{5}= & p I_{e} \int_{T_{1}}^{T} t D(t) d t+p I_{e}(m-T) \int_{T_{1}}^{T} D(t) d t=p I_{e}\left\{\frac{a}{2}\left(T^{2}-T_{1}^{2}\right)+\frac{b}{3}\left(T^{3}-T_{1}^{3}\right)\right\} \\
& +p I_{e}\left\{a\left(T-T_{1}\right)+\frac{b}{2}\left(T^{2}-T_{1}^{2}\right)\right\}
\end{aligned}
$$

Hence, the total average cost per unit time is

$$
\begin{aligned}
& Z_{5}\left(T_{1}, T\right)=\frac{1}{T}\left[k+D C+H C+S C-E_{5}\right] \\
& =\frac{1}{T}\left[k+c_{2}\left(1-\alpha T_{1}^{\beta}\right) \mu_{2}-c_{2} \mu_{2}+c_{2}\left\{\frac{a \alpha^{2}}{\xi_{1}} T_{1}^{\xi_{4}}+\frac{b \alpha^{2}}{\xi_{2}} T_{1}^{\xi_{5}}\right\}-c_{2} \alpha T_{1}^{\beta} \lambda_{8}\right. \\
& +h\left\{\frac{a \alpha}{\xi_{2}}\left(T^{\xi_{2}}-T_{1}^{\xi_{2}}\right)+\frac{b \alpha}{\xi_{3}}\left(T^{\xi_{3}}-T_{1}^{\xi_{3}}\right)+\frac{a \alpha^{2}}{\xi_{1} \xi_{5}}\left(T^{\xi_{5}}-T_{1}^{\xi_{5}}\right)+\frac{b \alpha^{2}}{\xi_{2} \xi_{6}}\left(T^{\xi_{6}}-T_{1}^{\xi_{6}}\right)\right\} \\
& -h\left\{\frac{a}{2}\left(T^{2}-T_{1}^{2}\right)+\frac{b}{6}\left(T^{3}-T_{1}^{3}\right)+\frac{a \alpha}{\xi_{1} \xi_{2}}\left(T^{\xi_{2}}-T_{1}^{\xi_{2}}\right)+\frac{b \alpha}{\xi_{2} \xi_{3}}\left(T^{\xi_{3}}-T_{1}^{\xi_{3}}\right)\right\} \\
& \left.\quad-p I_{e}\left\{\frac{a}{2}\left(T^{2}-T_{1}^{2}\right)+\frac{b}{3}\left(T^{3}-T_{1}^{3}\right)\right\}-\frac{h \alpha}{\beta} \mu_{1}\left(T^{\zeta_{1}}-T_{1}^{\zeta_{1}}\right)-p(m-T) \lambda_{8} I_{e}+s \tau\right]
\end{aligned}
$$

We have to minimize $Z_{5}\left(T_{1}, T\right)$. We use the following lemma for this purpose.

Lemma $5 Z_{5}\left(T_{1}, T\right)$ has the minimum value for those values of $T$ and $T_{1}$ which satisfy the following equations

(i) $c_{2} \mu_{3}-c_{2} \sigma T_{1}^{\zeta}\left(\lambda_{8}+\mu_{2}\right)-c_{2} \mu_{4}+c_{2} \alpha T_{1}^{\beta}\left(a+b T_{1}\right)+h \mu_{5}+h\left(\tau+\mu_{6}\right)$ $+\frac{h \alpha \zeta_{1}}{\beta} T_{1}^{\zeta_{2}} \mu_{1}+s\left(a+b T_{1}\right)+p I_{e}\left(a T_{1}+b T_{1}^{2}\right)+p I_{e}(m-T)(a+b T)=0$

(ii) $P-T c_{2} \mu_{4}\left(1-\alpha T_{1}^{\beta}\right)+T c_{2} \alpha T_{1}^{\beta}(a+b T)-h \mu_{7} T+T \mu_{1}\left\{p I_{r}+h+\frac{h \alpha \zeta_{1}}{\beta} T^{\zeta_{2}}\right\}$ $+p I_{e}\left(a T+b T^{2}\right)+\frac{h \alpha}{\beta}\left(T^{\zeta_{1}}-T_{1}^{\zeta_{1}}\right) \mu_{8}-p I_{e} \lambda_{8}+p I_{e}(m-T)(a+b T)=0$ 
provided they satisfy the following sufficient conditions

$$
\begin{aligned}
& \text { (iii) } c_{2} \mu_{9}-c_{2} \alpha \beta \zeta_{1} T_{1}^{\zeta_{2}}\left(\lambda_{8}+\mu_{6}\right)+2 c_{2} \sigma T_{1}^{\zeta_{1}}\left(a+b T_{1}\right)+c_{2} b \alpha T_{1}^{\beta}+h \mu_{10} \\
& +\frac{h \alpha \zeta_{1} \zeta_{2}}{\beta} \mu_{1} T_{1}^{\zeta_{3}}+s b+p I_{e}\left(a+2 b T_{1}\right)+p b(m-T) I_{e}>h \mu_{11}+c_{2} \lambda_{9} \\
& \text { (iv) }\left[c_{2} \mu_{9}+s b+p I_{e}\left(a+2 b T_{1}\right)+p b(m-T) I_{e}-c_{2} \alpha \beta \zeta_{1} T_{1}^{\zeta_{2}} \mu_{1}+2 c_{2} \sigma T_{1}^{\zeta_{1}}\left(a+b T_{1}\right)\right. \\
& \left.+c_{2} b \alpha T_{1}^{\beta}-c_{2} \mu_{12}+h \mu_{10}-h \mu_{11}+\frac{h \alpha \zeta_{1} \zeta_{2}}{\beta} \mu_{1} T_{1}^{\zeta_{3}}\right]\left[c_{2} \mu_{12}\left(1-\alpha T_{1}^{\beta}\right)-c_{2} \alpha b T_{1}^{\beta}\right. \\
& +h \mu_{13}-\left\{h+\frac{2 h \alpha \zeta_{1}}{\beta} T^{\zeta_{2}}\right\} \mu_{8}-p I_{e}(a+2 b T)-p b I_{e}(m-T)+2 p I_{e}(a+b T) \\
& \left.\quad-\frac{h \alpha \zeta_{1} \zeta_{2}}{\beta} \mu_{1} T^{\zeta_{3}}\right]>\left[\frac{h \alpha \zeta_{1}}{\beta}\left(b+\mu_{12}\right) T_{1}^{\zeta_{2}}-c_{2} \sigma T_{1}^{\zeta_{1}} \mu_{12}-c_{2} b \sigma T_{1}^{\zeta_{1}}\right]^{2}
\end{aligned}
$$

[See Appendix 2 for all values]

[See Appendix 7 for proof.]

\section{Numerical Examples}

Case 1 Let us take the following parametric values of this inventory model as $a=500$ units per year, $b=0.50$ units per year, $\alpha=0.002, \beta=1.5, k=\$ 100$ per order, $I_{r}=\$ 0.15$ per year, $I_{e}=\$ 0.13$ per year, $h=\$ 0.92$ per unit per year, $s=\$ 0.80$ per year, $c_{2}=0.2$ per unit per year, $p=\$ 10$ per unit and $m=0.30$ year.

Solving Eq. (11), we have $T_{1}^{*}=0.50$ year and $T^{*}=0.72$ year and the minimum average cost is $Z_{1}^{*}\left(T_{1}, T\right)=\$ 526.90$.

Case 2 Let us take the following parametric values of this inventory model as $a=500$ units per year, $b=0.50$ units per year, $\alpha=0.002, \beta=1.5, k=\$ 100$ per order, $I_{r}=\$ 0.15$ per year, $I_{e}=\$ 0.13$ per year, $h=\$ 0.92$ per unit per year, $s=\$ 0.80$ per year, $c_{2}=0.2$ per unit per year, $p=\$ 10$ per unit and $m=0.3$ year.

Solving Eq. (13), we have $T_{1}^{*}=0.24$ year and $T^{*}=0.60$ year and the minimum average cost is $Z_{2}^{*}\left(T_{1}, T\right)=\$ 341.31$.

Case 3 Let us take the following parametric values of this inventory model as $a=500$ units per year, $b=0.50$ units per year, $\alpha=0.002, \beta=1.5, k=\$ 100$ per order, $I_{r}=\$ 0.15$ per year, $I_{e}=\$ 0.13$ per year, $h=\$ 0.92$ per unit per year, $s=\$ 0.80$ per year, $c_{2}=0.2$ per unit per year, $p=\$ 10$ per unit and $m=0.30$ year.

Solving Eq. (15), we have $T_{1}^{*}=0.13$ year and $T^{*}=0.21$ year and the minimum average cost is $Z_{3}^{*}\left(T_{1}, T\right)=\$ 375.08$.

Case 4 Let us take the following parametric values of this inventory model as $a=500$ units per year, $b=0.50$ units per year, $\alpha=0.002, \beta=1.5, k=\$ 100$ per order, $I_{r}=\$ 0.15$ per year, $I_{e}=\$ 0.13$ per year, $h=\$ 0.92$ per unit per year, $s=\$ 0.80$ per year, $c_{2}=0.2$ per unit per year, $p=\$ 10$ per unit and $m=0.30$ year.

Solving Eq. (28), we have $T_{1}^{*}=0.25$ year and $T^{*}=0.41$ year and the minimum average cost is $Z_{4}^{*}\left(T_{1}, T\right)=\$ 255.97$.

Case 5 Let us take the following parametric values of this inventory model as $a=500$ units per year, $b=0.50$ units per year, $\alpha=0.002, \beta=1.5, k=\$ 100$ per order, $I_{r}=\$ 0.15$ per year, $I_{e}=\$ 0.13$ per year, $h=\$ 0.92$ per unit per year, $s=\$ 0.80$ per year, $c_{2}=0.2$ per unit per year, $p=\$ 10$ per unit and $m=0.30$ year. 
Solving Eq. (30), we have $T_{1}^{*}=0.2$ year and $T^{*}=0.27$ year and the minimum average cost is $Z_{5}^{*}\left(T_{1}, T\right)=\$ 283.82$.

\section{Conclusions}

Many physical goods are deteriorated over time. Electronics goods, radio-active substances, photographic film, grain etc. deteriorate through a gradual loss of potential with passage of time. Fruits, vegetables, foodstuff etc. suffer depletion by direct spoilage when they stored for a long time. Gasoline, petroleum, alcohol, etc. are highly perishable items. Thus decay or deterioration of physical goods held in stock is a very realistic area of researchers. This model assumed that the deterioration rate was a two-parameter Weibull distribution. This type of deterioration was justified for increasing rate, decreasing rate, or constant rate of deterioration for different choice of parameters of the distribution function.

The demand rate was taken to be time-dependent in contract to constant demand rate in other models. A linear trend in demand is of the form $D(t)=a+b t$ and it represents steady increase or decrease of demand rate over time. Thus it is certainly more realistic than constant demand in the real market. Shortages are very important for a managerial view. Some retailer allows shortages at the beginning of the planning period to avoid large holding cost or maintenance cost. Many retailers are compelled to allow shortages at the end of planning period. The allocation of cost savings is very important for the success of the joint relationship between the buyer and vendor in supply chain management. Facing a competitive commercial environment, many vendors and buyers would like to establish long-term cooperative relationships to obtain stable sources of supply and demand to gain the optimum profit from each other. Traditional inventory models usually hypothesize that the buyer pays the vendor immediately when the items purchased are received. However, in practice, the vendor often gives the buyer a delay payment period to promote the buyer increasing the order quantity. Therefore, Delay-in-payments to the supplier is alternative ways of price discount for retailers, especially small businesses which tend to have a limited number of financing opportunities, rely on trade-credit as a source of short-term funds. Also, the managers of big suppliers are to take appropriate decisions for the different delay-period under different situation to encourage the retailer to run smooth business. Also, they have to face some difficulties like shortages, deterioration of products, inflation, etc.

This model studied a comparative study between IFS policy and SFI policy with the presence of stochastic deterioration of products. The deterioration rate followed a two-parameter Weibull deterioration. An attempt was made by assuming trade-credit financing in this comparative study. This study found that the total cost of the model starting with shortages is less than the total cost of the model starting with no shortages. The proposed model can be extended in several ways. For example, we may assume probabilistic demand and a finite rate of replenishment. Also quantity discounts, time value of money and inflation, etc. may be added in this paper for further study.

\section{Appendix 1}

Proof We have $V\left(T_{1}, T\right)=\frac{1}{T} G\left(T_{1}, T\right)$. For the minimum value of $V\left(T_{1}, T\right)$ at $T_{1}=$ $T_{1}^{*}, T=T^{*}$, necessary conditions are $\frac{\partial V\left(T_{1}, T\right)}{\partial T_{1}}=0$, and $\frac{\partial V\left(T_{1}, T\right)}{\partial T}=0$. 
Now

$$
\frac{\partial V\left(T_{1}, T\right)}{\partial T}=\frac{T \frac{\partial G\left(T_{1}, T\right)}{\partial T}-G\left(T_{1}, T\right)}{T^{2}} \text { and } \frac{\partial V\left(T_{1}, T\right)}{\partial T_{1}}=\frac{1}{T} \frac{\partial G\left(T_{1}, T\right)}{\partial T_{1}}
$$

Therefore,

$$
\frac{\partial V\left(T_{1}, T\right)}{\partial T}=0 \text { gives } T \frac{\partial G\left(T_{1}, T\right)}{\partial T}-G\left(T_{1}, T\right)=0
$$

and $\frac{\partial V\left(T_{1}, T\right)}{\partial T_{1}}=0$ gives $\frac{\partial G\left(T_{1}, T\right)}{\partial T_{1}}=0$.

Equations are satisfied for $T=T^{*}$ and $T_{1}=T_{1}^{*}$.

Again,

$$
\frac{\partial^{2} V\left(T_{1}, T\right)}{\partial T^{2}}=\frac{T\left(T \frac{\partial^{2} G\left(T_{1}, T\right)}{\partial T^{2}}+\frac{\partial G\left(T_{1}, T\right)}{\partial T}-\frac{\partial G\left(T_{1}, T\right)}{\partial T}\right)-2 T\left(T \frac{\partial G\left(T_{1}, T\right)}{\partial T}-G\left(T_{1}, T\right)\right)}{T^{4}}
$$

Thus, at $T=T^{*}$ and $T_{1}=T_{1}^{*}$, we have

$$
\frac{\partial^{2} V\left(T_{1}, T\right)}{\partial T^{2}}=\frac{1}{T} \frac{\partial^{2} G\left(T_{1}, T\right)}{\partial T^{2}}
$$

Similarly, at $T=T^{*}$ and

$$
T_{1}=T_{1}^{*}, \frac{\partial^{2} V\left(T_{1}, T\right)}{\partial T_{1}^{2}}=\frac{1}{T} \frac{\partial^{2} G\left(T_{1}, T\right)}{\partial T_{1}^{2}}
$$

and

$$
\frac{\partial^{2} V\left(T_{1}, T\right)}{\partial T \partial T_{1}}=\frac{1}{T} \frac{\partial^{2} G\left(T_{1}, T\right)}{\partial T \partial T_{1}}
$$

Hence,

$$
\left|\begin{array}{ll}
\frac{\partial^{2} V\left(T_{1}, T\right)}{\partial T_{1}^{2}} & \frac{\partial^{2} V\left(T_{1}, T\right)}{\partial T_{1} \partial T} \\
\frac{\partial^{2} V\left(T_{1}, T\right)}{\partial T_{1} \partial T} & \frac{\partial^{2} V\left(T_{1}, T\right)}{\partial T^{2}}
\end{array}\right|=\left|\begin{array}{ll}
\frac{1}{T} \frac{\partial^{2} G\left(T_{1}, T\right)}{\partial T_{1}^{2}} & \frac{1}{T} \frac{\partial^{2} G\left(T_{1}, T\right)}{\partial T_{1} \partial T} \\
\frac{1}{T} \frac{\partial^{2} G\left(T_{1}, T\right)}{\partial T_{1} \partial T} & \frac{1}{T} \frac{\partial^{2} G\left(T_{1}, T\right)}{\partial T^{2}}
\end{array}\right|=\frac{1}{T^{2}}\left|\begin{array}{ll}
\frac{\partial^{2} G\left(T_{1}, T\right)}{\partial T_{1}^{2}} & \frac{\partial^{2} G\left(T_{1}, T\right)}{\partial T_{1} \partial T} \\
\frac{\partial^{2} G\left(T_{1}, T\right)}{\partial T_{1} \partial T} & \frac{\partial^{2} G\left(T_{1}, T\right)}{\partial T^{2}}
\end{array}\right|
$$

Thus, if

$$
\left|\begin{array}{ll}
\frac{\partial^{2} G\left(T_{1}, T\right)}{\partial T_{1}^{2}} & \frac{\partial^{2} G\left(T_{1}, T\right)}{\partial T_{1} \partial T} \\
\frac{\partial^{2} G\left(T_{1}, T\right)}{\partial T_{1} \partial T} & \frac{\partial^{2} G\left(T_{1}, T\right)}{\partial T^{2}}
\end{array}\right|>0 \text { and } \frac{\partial^{2} G\left(T_{1}, T\right)}{\partial T_{1}^{2}}>0
$$

then

$$
\left|\begin{array}{ll}
\frac{\partial^{2} V\left(T_{1}, T\right)}{\partial T_{1}^{2}} & \frac{\partial^{2} V\left(T_{1}, T\right)}{\partial T_{1} \partial T} \\
\frac{\partial^{2} V\left(T_{1}, T\right)}{\partial T_{1} \partial T} & \frac{\partial^{2} V\left(T_{1}, T\right)}{\partial T^{2}}
\end{array}\right|>0 \text { and } \frac{\partial^{2} V\left(T_{1}, T\right)}{\partial T_{1}^{2}}>0
$$

which indicates $V\left(T_{1}, T\right)$ is minimum. 


\section{Appendix 2}

$$
\begin{aligned}
& \xi_{1}=\beta+1 \text {, } \\
& \xi_{4}=2 \beta+1 \text {, } \\
& \xi_{2}=\beta+2 \text {, } \\
& \xi_{5}=2 \beta+2 \text {, } \\
& \xi_{3}=\beta+3 \text {, } \\
& \xi_{6}=2 \beta+3 \text {, } \\
& \zeta_{1}=\beta-1 \text {, } \\
& \zeta_{2}=\beta-2 \text {, } \\
& \zeta_{3}=\beta-3 \text {, } \\
& \alpha \beta=\sigma \text {, } \\
& \tau=a T_{1}+\frac{b}{2} T_{1}^{2} \\
& I_{0}=a T_{1}+\frac{b}{2} T_{1}^{2}+\frac{a \alpha}{\xi_{1}} T_{1}^{\xi_{1}}+\frac{b \alpha}{\xi_{2}} T_{1}^{\xi_{2}}, \\
& \lambda_{1}=a \alpha T_{1}^{\beta}+b \alpha T_{1}^{\beta+1}, \\
& \lambda_{2}=a T_{1}+b T_{1}^{2}-a T-b T_{1} T, \\
& \lambda_{3}=a+b T_{1}+a \alpha T_{1}^{\beta}+b \alpha T_{1}^{\beta+1}, \\
& \lambda_{4}=I_{0}-a T_{1}+\frac{b}{2} T_{1}^{2}, \\
& \lambda_{5}=\left\{\frac{a}{2} T_{1}^{2}+\frac{b}{3} T_{1}^{3}+\frac{a \alpha \beta}{(\beta+1)(\beta+2)} T_{1}^{\beta+2}+\frac{b \alpha \beta}{(\beta+1)(\beta+3)} T_{1}^{\beta+3}\right. \\
& \left.-\frac{a \alpha^{2}}{(\beta+1)(2 \beta+2)} T_{1}^{2 \beta+2}-\frac{b \alpha^{2}}{(\beta+2)(2 \beta+3)} T_{1}^{2 \beta+3}\right\}, \\
& \lambda_{6}=\left\{I_{0}\left(T_{1}-m\right)-\frac{a}{2}\left(T_{1}^{2}-m^{2}\right)-\frac{b}{6}\left(T_{1}^{3}-m^{3}\right)-\frac{I_{0} \alpha}{\beta+1}\left(T_{1}^{\beta+1}-m^{\beta+1}\right)\right. \\
& +\frac{a \alpha \beta}{(\beta+1)(\beta+2)}\left(T_{1}^{\beta+2}-m^{\beta+2}\right)+\frac{b \alpha \beta}{2(\beta+2)(\beta+3)}\left(T_{1}^{\beta+3}-m^{\beta+3}\right) \\
& \left.+\frac{a \alpha^{2}}{(\beta+1)(2 \beta+2)}\left(T_{1}^{2 \beta+2}-m^{2 \beta+2}\right)+\frac{b \alpha^{2}}{(\beta+2)(2 \beta+3)}\left(T_{1}^{2 \beta+3}-m^{2 \beta+3}\right)\right\} \text {, } \\
& \lambda_{7}=\frac{a}{2} m^{2}+\frac{b}{3} m^{3}, \\
& \lambda_{8}=a\left(T-T_{1}\right)+\frac{b}{2}\left(T^{2}-T_{1}^{2}\right), \\
& \lambda_{9}=\left\{a \alpha \beta T_{1}^{\beta-1}+b \alpha(\beta+1) T_{1}^{\beta}\right\}, \\
& \lambda_{10}=a+2 b T_{1}+a \alpha \beta T_{1}^{\beta} \text {, } \\
& \lambda_{11}=a+2 b T_{1}-b T \text {, }
\end{aligned}
$$




$$
\begin{aligned}
& \lambda_{12}=\frac{a}{2} T_{1}^{2}+\frac{b}{6} T_{1}^{3}, \\
& \eta=\left\{\frac{a}{2}\left(T^{2}-T_{1}^{2}\right)+\frac{b}{6}\left(T^{3}-T_{1}^{3}\right)-\left(T-T_{1}\right)\left(a T+\frac{b}{2} T^{2}\right)\right\}, \\
& I_{1}=\left\{a\left(T-T_{1}\right)+\frac{b}{2}\left(T^{2}-T_{1}^{2}\right)+\frac{a \alpha}{\xi_{1}}\left(T^{\xi_{1}}-T_{1}^{\xi_{1}}\right)+\frac{b \alpha}{\xi_{2}}\left(T^{\xi_{2}}-T_{1}^{\xi_{2}}\right)\right\} \exp \left\{-\alpha T_{1}^{\beta}\right\}, \\
& \mu_{1}=a T+\frac{b}{2} T^{2}+\frac{a \alpha}{(\beta+1)} T^{\beta+1}+\frac{b \alpha}{(\beta+2)} T^{\beta+2}, \\
& \mu_{2}=\frac{a \alpha}{(\beta+1)} T^{\beta+1}+\frac{b \alpha}{(\beta+2)} T^{\beta+2}, \\
& \mu_{3}=\left\{\frac{a \alpha^{2}(2 \beta+1)}{\beta+1} T_{1}^{2 \beta}+\frac{b \alpha^{2}(2 \beta+2)}{\beta+2} T_{1}^{2 \beta+1}\right\}, \\
& \mu_{4}=a \alpha T_{1}^{\beta}+b \alpha T_{1}^{\beta+1}, \\
& \mu_{5}=\left\{a \alpha T_{1}^{\beta+1}+\frac{b \alpha}{2} T_{1}^{\beta+2}+\frac{a \alpha^{2}}{\beta+1} T_{1}^{2 \beta+1}+\frac{b \alpha^{2}}{\beta+2} T_{1}^{2 \beta+2}\right\}, \\
& \mu_{6}=\frac{a \alpha}{(\beta+1)} T_{1}^{\beta+1}+\frac{b \alpha}{(\beta+2)} T_{1}^{\beta+2} \text {, } \\
& \mu_{7}=\left\{a \alpha T^{\beta+1}+\frac{b \alpha}{2} T^{\beta+2}+\frac{a \alpha^{2}}{(\beta+1)} T^{2 \beta+1}+\frac{b \alpha^{2}}{(\beta+2)} T^{2 \beta+2}\right\}, \\
& \mu_{8}=a+b T+a \alpha T^{\beta}+b \alpha T^{\beta+1} \text {, } \\
& \mu_{9}=\left\{\frac{a \alpha^{2} 2 \beta(2 \beta+1)}{(\beta+1)} T_{1}^{2 \beta-1}+\frac{b \alpha^{2}(2 \beta+1)(2 \beta+2)}{(\beta+2)} T_{1}^{2 \beta}\right\}, \\
& \mu_{10}=a T+b T_{1}+a \alpha T_{1}^{\beta}+b \alpha T_{1}^{\beta+1}, \\
& \mu_{11}=\left\{a \alpha(\beta+1) T_{1}^{\beta}+\frac{b \alpha(\beta+2)}{2} T_{1}^{\beta+1}+\frac{a \alpha^{2}(2 \beta+1)}{(\beta+1)} T_{1}^{2 \beta}+\frac{b \alpha^{2}(2 \beta+2)}{\beta+2} T_{1}^{2 \beta+1}\right\}, \\
& \mu_{12}=b+a \alpha \beta T^{\beta-1}+b \alpha(\beta+1) T^{\beta}, \\
& \mu_{13}=\left\{a \alpha(\beta+1) T^{\beta}+\frac{b \alpha(\beta+2)}{2} T^{\beta+1}+\frac{a \alpha^{2}(2 \beta+1)}{(\beta+1)} T^{2 \beta}+\frac{b \alpha^{2}(2 \beta+2)}{\beta+2} T^{2 \beta+1}\right\},
\end{aligned}
$$

\section{Appendix 3}

Proof To minimize $Z_{1}\left(T_{1}, T\right)=\frac{1}{T} F_{1}\left(T_{1}, T\right)$, we have necessary conditions as $\frac{\partial Z_{1}\left(T_{1}, T\right)}{\partial T_{1}}=$ $0, \frac{\partial Z_{1}\left(T_{1}, T\right)}{\partial T}=0$ and from the above theorem the sufficient conditions are $\frac{\partial^{2} F_{1}\left(T_{1}, T\right)}{\partial T_{1}^{2}}>0$ and $\left|\begin{array}{ll}\frac{\partial^{2} F_{1}\left(T_{1}, T\right)}{\partial T_{1}^{2}} & \frac{\partial^{2} F_{1}\left(T_{1}, T\right)}{\partial T_{1} \partial T} \\ \frac{\partial^{2} F_{1}\left(T_{1}, T\right)}{\partial T_{1} \partial T} & \frac{\partial^{2} F_{1}\left(T_{1}, T\right)}{\partial T^{2}}\end{array}\right|>0$

Now $\frac{\partial Z_{1}\left(T_{1}, T\right)}{\partial T_{1}}=0$ gives

(i) $c_{2}\left(a \alpha T_{1}^{\beta}+b \alpha T_{1}^{\beta+1}\right)+h\left\{a T_{1}+b T_{1}^{2}+\frac{a \alpha \beta}{\beta+1} T_{1}^{\beta+1}+\frac{b \alpha \beta}{\beta+1} T_{1}^{\beta+2}-\frac{a \alpha^{2}}{\beta+1} T_{1}^{2 \beta+1}\right.$ 


$$
\begin{aligned}
& \left.-\frac{b \alpha^{2}}{\beta+2} T_{1}^{2 \beta+2}\right\}+s\left\{a T_{1}+b T_{1}^{2}-a T-b T_{1} T\right\}+p I_{r}\left\{\left(a+b T_{1}+a \alpha T_{1}^{\beta}+b \alpha T_{1}^{\beta+1}\right)\right. \\
& \left.\left(T_{1}-m-\frac{\alpha}{\beta+1} T_{1}^{\beta+1}+\frac{\alpha}{\beta+1} m^{\beta+1}\right)+I_{0}\left(1-\alpha T_{1}^{\beta}\right)-\left(a T_{1}+\frac{b}{2} T_{1}^{2}\right)\right\}=0
\end{aligned}
$$

Also, $\frac{\partial Z_{1}\left(T_{1}, T\right)}{\partial T}=0$ gives

$$
\begin{aligned}
& \text { (ii) } k+c_{2}\left(I_{0}-a T_{1}+\frac{b}{2} T_{1}^{2}\right)+h\left\{\frac{a}{2} T_{1}^{2}+\frac{b}{3} T_{1}^{3}+\frac{a \alpha \beta}{(\beta+1)(\beta+2)} T_{1}^{\beta+2}\right. \\
& \left.+\frac{b \alpha \beta}{(\beta+1)(\beta+3)} T_{1}^{\beta+3}-\frac{a \alpha^{2}}{(\beta+1)(2 \beta+2)} T_{1}^{2 \beta+2}-\frac{b \alpha^{2}}{(\beta+2)(2 \beta+3)} T_{1}^{2 \beta+3}\right\} \\
& +s\left\{\frac{a}{2}\left(T^{2}-T_{1}^{2}\right)+\frac{b}{6}\left(T^{3}-T_{1}^{3}\right)-\left(T-T_{1}\right)\left(a T+\frac{b}{2} T^{2}\right)\right\} \\
& +p I_{r}\left\{I_{0}\left(T_{1}-m\right)-\frac{a}{2}\left(T_{1}^{2}-m^{2}\right)-\frac{b}{6}\left(T_{1}^{3}-m^{3}\right)-\frac{I_{0} \alpha}{\beta+1}\left(T_{1}^{\beta+1}-m^{\beta+1}\right)\right. \\
& +\frac{a \alpha \beta}{(\beta+1)(\beta+2)}\left(T_{1}^{\beta+2}-m^{\beta+2}\right) \\
& +\frac{b \alpha \beta}{2(\beta+2)(\beta+3)}\left(T_{1}^{\beta+3}-m^{\beta+3}\right)+\frac{a \alpha^{2}}{(\beta+1)(2 \beta+2)}\left(T_{1}^{2 \beta+2}-m^{2 \beta+2}\right) \\
& \left.+\frac{b \alpha^{2}}{(\beta+2)(2 \beta+3)}\left(T_{1}^{2 \beta+3}-m^{2 \beta+3}\right)\right\}-p I_{e}\left(\frac{a}{2} m^{2}+\frac{b}{3} m^{3}\right) \\
& -T s\left\{a\left(T-T_{1}\right)+\frac{b}{2}\left(T^{2}-T_{1}^{2}\right)\right\}=0
\end{aligned}
$$

To obtain optimal values for $T_{1}$ and $T$, we have to solve the above two equations provided they satisfy the following sufficient conditions.

Using the above theorem,

$$
\frac{\partial^{2} F_{1}\left(T_{1}, T\right)}{\partial T_{1}^{2}}>0, \text { and }\left|\begin{array}{ll}
\frac{\partial^{2} F_{1}\left(T_{1}, T\right)}{\partial T_{1}^{2}} & \frac{\partial^{2} F_{1}\left(T_{1}, T\right)}{\partial T_{1} \partial T} \\
\frac{\partial^{2} F_{1}\left(T_{1}, T\right)}{\partial T_{1} \partial T} & \frac{\partial^{2} F_{1}\left(T_{1}, T\right)}{\partial T^{2}}
\end{array}\right|>0
$$

we obtain the following results

$$
\begin{aligned}
& \text { (iii) } c_{2}\left\{a \alpha \beta T_{1}^{\beta-1}+b \alpha(\beta+1) T_{1}^{\beta}\right\}+h\left\{a+2 b T_{1}+a \alpha \beta T_{1}^{\beta}+\frac{b \alpha \beta(\beta+2)}{\beta+1} T_{1}^{\beta+1}\right. \\
& \left.-\frac{a \alpha^{2}(2 \beta+1)}{(\beta+1)} T_{1}^{2 \beta}-\frac{b \alpha^{2}(2 \beta+2)}{(\beta+2)} T_{1}^{2 \beta+1}\right\} p I_{r}\left\{b+a \alpha \beta T_{1}^{\beta-1}+b \alpha(\beta+1) T_{1}^{\beta}\right\} . \\
& \left\{T_{1}-m-\frac{\alpha}{(\beta+1)} T_{1}^{\beta+1}+\frac{\alpha}{(\beta+1)} m^{\beta+1}\right\}+s\left\{a+2 b T_{1}-b T\right\} \\
& >p \alpha I_{r}\left(a+b T_{1}+a \alpha T_{1}^{\beta}+b \alpha T_{1}^{\beta+1}\right) T_{1}^{\beta}+I_{0} \alpha \beta T_{1}^{\beta-1}+\left(a+b T_{1}\right)
\end{aligned}
$$


and

$$
\text { (iv) } \begin{aligned}
& {\left[c_{2}\left\{a \alpha \beta T_{1}^{\beta-1}+b \alpha(\beta+1) T_{1}^{\beta}\right\}+h\left\{a+2 b T_{1}+a \alpha \beta T_{1}^{\beta}+\frac{b \alpha \beta(\beta+2)}{\beta+1} T_{1}^{\beta+1}\right.\right.} \\
& \left.-\frac{a \alpha^{2}(2 \beta+1)}{(\beta+1)} T_{1}^{2 \beta}-\frac{b \alpha^{2}(2 \beta+2)}{(\beta+2)} T_{1}^{2 \beta+1}\right\}+p I_{r}\left\{b+a \alpha \beta T_{1}^{\beta-1}+b \alpha(\beta+1) T_{1}^{\beta}\right\} \\
& \left\{T_{1}-m-\frac{\alpha}{(\beta+1)} T_{1}^{\beta+1}+\frac{\alpha}{(\beta+1)} m^{\beta+1}\right\}+s\left\{a+2 b T_{1}-b T\right\} \\
& \left.-p \alpha I_{r}\left(a+b T_{1}+a \alpha T_{1}^{\beta}+b \alpha T_{1}^{\beta+1}\right) T_{1}^{\beta}-I_{0} \alpha \beta T_{1}^{\beta-1}-\left(a+b T_{1}\right)\right](a+b T) \\
> & s\left(a+b T_{1}\right)^{2}
\end{aligned}
$$

\section{Appendix 4}

Proof To minimize $Z_{2}\left(T_{1}, T\right)=\frac{1}{T} F_{2}\left(T_{1}, T\right)$, we have necessary conditions as $\frac{\partial Z_{2}\left(T_{1}, T\right)}{\partial T_{1}}=$ $0, \frac{\partial Z_{2}\left(T_{1}, T\right)}{\partial T}=0$ and from the above theorem the sufficient conditions are $\frac{\partial^{2} F_{2}\left(T_{1}, T\right)}{\partial T_{1}^{2}}>0$ and $\left|\begin{array}{ll}\frac{\partial^{2} F_{2}\left(T_{1}, T\right)}{\partial T_{1}^{2}} & \frac{\partial^{2} F_{2}\left(T_{1}, T\right)}{\partial T_{1} \partial T} \\ \frac{\partial^{2} F_{2}\left(T_{1}, T\right)}{\partial T_{1} \partial T} & \frac{\partial^{2} F_{2}\left(T_{1}, T\right)}{\partial T^{2}}\end{array}\right|>0$

Now $\frac{\partial Z_{2}\left(T_{1}, T\right)}{\partial T_{1}}=0$ gives

(i) $c_{2}\left(a \alpha T_{1}^{\beta}+b \alpha T_{1}^{\beta+1}\right)+h\left\{a T_{1}+b T_{1}^{2}+\frac{a \alpha \beta}{\beta+1} T_{1}^{\beta+1}+\frac{b \alpha \beta}{\beta+1} T_{1}^{\beta+2}-\frac{a \alpha^{2}}{\beta+1} T_{1}^{2 \beta+1}\right.$

$$
\left.-\frac{b \alpha^{2}}{\beta+2} T_{1}^{2 \beta+2}\right\}+s\left\{a T_{1}+b T_{1}^{2}-a T-b T_{1} T\right\}+p I_{e}\left(a T_{1}+\frac{b}{2} T_{1}^{2}\right)
$$

$-p m I_{e}\left(a+b T_{1}\right)=0$

Also, $\frac{\partial Z_{2}\left(T_{1}, T\right)}{\partial T}=0$ gives

$$
\begin{aligned}
\text { (ii) } & k+c_{2}\left(I_{0}-a T_{1}+\frac{b}{2} T_{1}^{2}\right)+h\left\{\frac{a}{2} T_{1}^{2}+\frac{b}{3} T_{1}^{3}+\frac{a \alpha \beta}{(\beta+1)(\beta+2)} T_{1}^{\beta+2}\right. \\
+ & \left.\frac{b \alpha \beta}{(\beta+1)(\beta+3)} T_{1}^{\beta+3}-\frac{a \alpha^{2}}{(\beta+1)(2 \beta+2)} T_{1}^{2 \beta+2}-\frac{b \alpha^{2}}{(\beta+2)(2 \beta+3)} T_{1}^{2 \beta+3}\right\} \\
+ & s\left\{\frac{a}{2}\left(T^{2}-T_{1}^{2}\right)+\frac{b}{6}\left(T^{3}-T_{1}^{3}\right)-\left(T-T_{1}\right)\left(a T+\frac{b}{2} T^{2}\right)\right\} \\
+ & p I_{r}\left\{I_{0}\left(T_{1}-m\right)-\frac{a}{2}\left(T_{1}^{2}-m^{2}\right)-\frac{b}{6}\left(T_{1}^{3}-m^{3}\right)-\frac{I_{0} \alpha}{\beta+1}\left(T_{1}^{\beta+1}-m^{\beta+1}\right)\right. \\
+ & \frac{a \alpha \beta}{(\beta+1)(\beta+2)}\left(T_{1}^{\beta+2}-m^{\beta+2}\right)+\frac{b \alpha \beta}{2(\beta+2)(\beta+3)}\left(T_{1}^{\beta+3}-m^{\beta+3}\right) \\
+ & \left.\frac{a \alpha^{2}}{(\beta+1)(2 \beta+2)}\left(T_{1}^{2 \beta+2}-m^{2 \beta+2}\right)+\frac{b \alpha^{2}}{(\beta+2)(2 \beta+3)}\left(T_{1}^{2 \beta+3}-m^{2 \beta+3}\right)\right\} \\
- & p I_{e}\left(\frac{a}{2} m^{2}+\frac{b}{3} m^{3}\right)-T s\left\{a\left(T-T_{1}\right)+\frac{b}{2}\left(T^{2}-T_{1}^{2}\right)\right\}=0
\end{aligned}
$$


To obtain optimal values for $T_{1}$ and $T$, we have to solve the above two equations provided they satisfy the following sufficient conditions.

Using the above theorem,

$$
\frac{\partial^{2} F_{2}\left(T_{1}, T\right)}{\partial T_{1}^{2}}>0, \text { and }\left|\begin{array}{ll}
\frac{\partial^{2} F_{2}\left(T_{1}, T\right)}{\partial T_{1}^{2}} & \frac{\partial^{2} F_{2}\left(T_{1}, T\right)}{\partial T_{1} \partial T} \\
\frac{\partial^{2} F_{2}\left(T_{1}, T\right)}{\partial T_{1} \partial T} & \frac{\partial^{2} F_{2}\left(T_{1}, T\right)}{\partial T^{2}}
\end{array}\right|>0
$$

we obtain the following results

$$
\begin{aligned}
& \text { (iii) } c_{2}\left\{a \alpha \beta T_{1}^{\beta-1}+b \alpha(\beta+1) T_{1}^{\beta}\right\}+h\left\{a+2 b T_{1}+a \alpha \beta T_{1}^{\beta}+\frac{b \alpha \beta(\beta+2)}{\beta+1} T_{1}^{\beta+1}\right. \\
& \left.-\frac{a \alpha^{2}(2 \beta+1)}{(\beta+1)} T_{1}^{2 \beta}-\frac{b \alpha^{2}(2 \beta+2)}{(\beta+2)} T_{1}^{2 \beta+1}\right\}+s\left\{a+2 b T_{1}-b T\right\}+p I_{e}\left(a+b T_{1}\right) \\
& >\operatorname{pbmI}_{e}
\end{aligned}
$$

and

$$
\begin{aligned}
\text { (iv) } & {\left[c_{2}\left\{a \alpha \beta T_{1}^{\beta-1}+b \alpha(\beta+1) T_{1}^{\beta}\right\}+h\left\{a+2 b T_{1}+a \alpha \beta T_{1}^{\beta}+\frac{b \alpha \beta(\beta+2)}{\beta+1} T_{1}^{\beta+1}\right.\right.} \\
- & \left.\frac{a \alpha^{2}(2 \beta+1)}{(\beta+1)} T_{1}^{2 \beta}-\frac{b \alpha^{2}(2 \beta+2)}{(\beta+2)} T_{1}^{2 \beta+1}\right\}+s\left\{a+2 b T_{1}-b T\right\}+p I_{e}\left(a+b T_{1}\right) \\
- & \left.p b m I_{e}\right](a+b T)>s\left(a+b T_{1}\right)^{2}
\end{aligned}
$$

\section{Appendix 5}

Proof To minimize $Z_{3}\left(T_{1}, T\right)=\frac{1}{T} F_{3}\left(T_{1}, T\right)$, we have necessary conditions as $\frac{\partial Z_{3}\left(T_{1}, T\right)}{\partial T_{1}}=0, \frac{\partial Z_{3}\left(T_{1}, T\right)}{\partial T}=0$ and from the above theorem the sufficient conditions are $\frac{\partial^{2} F_{3}\left(T_{1}, T\right)}{\partial T_{1}^{2}}>0$ and $\left|\begin{array}{ll}\frac{\partial^{2} F_{3}\left(T_{1}, T\right)}{\partial T_{1}^{2}} & \frac{\partial^{2} F_{3}\left(T_{1}, T\right)}{\partial T_{1} \partial T} \\ \frac{\partial^{2} F_{3}\left(T_{1}, T\right)}{\partial T_{1} \partial T} & \frac{\partial^{2} F_{3}\left(T_{1}, T\right)}{\partial T^{2}}\end{array}\right|>0$

Now $\frac{\partial Z_{3}\left(T_{1}, T\right)}{\partial T_{1}}=0$ gives

(i) $c_{2}\left(a \alpha T_{1}^{\beta}+b \alpha T_{1}^{\beta+1}\right)+h\left\{a T_{1}+b T_{1}^{2}+\frac{a \alpha \beta}{\beta+1} T_{1}^{\beta+1}+\frac{b \alpha \beta}{\beta+1} T_{1}^{\beta+2}-\frac{a \alpha^{2}}{\beta+1} T_{1}^{2 \beta+1}\right.$

$$
\begin{aligned}
& \left.-\frac{b \alpha^{2}}{\beta+2} T_{1}^{2 \beta+2}\right\}+s\left\{a T_{1}+b T_{1}^{2}-a T-b T_{1} T\right\}+p I_{e}\left(a T_{1}+\frac{b}{2} T_{1}^{2}\right) \\
& -p m I_{e}\left(a+b T_{1}\right)=0
\end{aligned}
$$

Also, $\frac{\partial Z_{3}\left(T_{1}, T\right)}{\partial T}=0$ gives

$$
\text { (ii) } \begin{aligned}
& k+c_{2}\left(I_{0}-a T_{1}+\frac{b}{2} T_{1}^{2}\right)+h\left\{\frac{a}{2} T_{1}^{2}+\frac{b}{3} T_{1}^{3}+\frac{a \alpha \beta}{(\beta+1)(\beta+2)} T_{1}^{\beta+2}\right. \\
& \left.+\frac{b \alpha \beta}{(\beta+1)(\beta+3)} T_{1}^{\beta+3}-\frac{a \alpha^{2}}{(\beta+1)(2 \beta+2)} T_{1}^{2 \beta+2}-\frac{b \alpha^{2}}{(\beta+2)(2 \beta+3)} T_{1}^{2 \beta+3}\right\} \\
+ & s\left\{\frac{a}{2}\left(T^{2}-T_{1}^{2}\right)+\frac{b}{6}\left(T^{3}-T_{1}^{3}\right)-\left(T-T_{1}\right)\left(a T+\frac{b}{2} T^{2}\right)\right\}
\end{aligned}
$$




$$
\begin{aligned}
& +p I_{r}\left\{I_{0}\left(T_{1}-m\right)-\frac{a}{2}\left(T_{1}^{2}-m^{2}\right)-\frac{b}{6}\left(T_{1}^{3}-m^{3}\right)-\frac{I_{0} \alpha}{\beta+1}\left(T_{1}^{\beta+1}-m^{\beta+1}\right)\right. \\
& +\frac{a \alpha \beta}{(\beta+1)(\beta+2)}\left(T_{1}^{\beta+2}-m^{\beta+2}\right)+\frac{b \alpha \beta}{2(\beta+2)(\beta+3)}\left(T_{1}^{\beta+3}-m^{\beta+3}\right) \\
& \left.+\frac{a \alpha^{2}}{(\beta+1)(2 \beta+2)}\left(T_{1}^{2 \beta+2}-m^{2 \beta+2}\right)+\frac{b \alpha^{2}}{(\beta+2)(2 \beta+3)}\left(T_{1}^{2 \beta+3}-m^{2 \beta+3}\right)\right\} \\
& -p I_{e}\left(\frac{a}{2} m^{2}+\frac{b}{3} m^{3}\right)-T s\left\{a\left(T-T_{1}\right)+\frac{b}{2}\left(T^{2}-T_{1}^{2}\right)\right\}=0
\end{aligned}
$$

To obtain optimal values for $T_{1}$ and $T$, we have to solve the above two equations provided they satisfy the following sufficient conditions.

Using the above theorem,

$$
\frac{\partial^{2} F_{3}\left(T_{1}, T\right)}{\partial T_{1}^{2}}>0, \text { and }\left|\begin{array}{ll}
\frac{\partial^{2} F_{3}\left(T_{1}, T\right)}{\partial T_{1}^{2}} & \frac{\partial^{2} F_{3}\left(T_{1}, T\right)}{\partial T_{1} \partial T} \\
\frac{\partial^{2} F_{3}\left(T_{1}, T\right)}{\partial T_{1} \partial T} & \frac{\partial^{2} F_{3}\left(T_{1}, T\right)}{\partial T^{2}}
\end{array}\right|>0
$$

we obtain the following results

$$
\begin{aligned}
\text { (iii) } & c_{2}\left\{a \alpha \beta T_{1}^{\beta-1}+b \alpha(\beta+1) T_{1}^{\beta}\right\}+h\left\{a+2 b T_{1}+a \alpha \beta T_{1}^{\beta}+\frac{b \alpha \beta(\beta+2)}{\beta+1} T_{1}^{\beta+1}\right. \\
& \left.-\frac{a \alpha^{2}(2 \beta+1)}{(\beta+1)} T_{1}^{2 \beta}-\frac{b \alpha^{2}(2 \beta+2)}{(\beta+2)} T_{1}^{2 \beta+1}\right\}+s\left\{a+2 b T_{1}-b T\right\}+p I_{e}\left(a+b T_{1}\right) \\
> & p b m I_{e}
\end{aligned}
$$

and

$$
\begin{aligned}
& \text { (iv) }\left[c_{2}\left\{a \alpha \beta T_{1}^{\beta-1}+b \alpha(\beta+1) T_{1}^{\beta}\right\}+h\left\{a+2 b T_{1}+a \alpha \beta T_{1}^{\beta}+\frac{b \alpha \beta(\beta+2)}{\beta+1} T_{1}^{\beta+1}\right.\right. \\
& \left.-\frac{a \alpha^{2}(2 \beta+1)}{(\beta+1)} T_{1}^{2 \beta}-\frac{b \alpha^{2}(2 \beta+2)}{(\beta+2)} T_{1}^{2 \beta+1}\right\}+s\left\{a+2 b T_{1}-b T\right\}+p I_{e}\left(a+b T_{1}\right) \\
& \left.-p b m I_{e}\right](a+b T)>s\left(a+b T_{1}\right)^{2}
\end{aligned}
$$

\section{Appendix 6}

Proof To minimize $Z_{4}\left(T_{1}, T\right)=\frac{1}{T} F_{4}\left(T_{1}, T\right)$, we have necessary conditions as $\frac{\partial Z_{4}\left(T_{1}, T\right)}{\partial T_{1}}=$ $0, \frac{\partial Z_{4}\left(T_{1}, T\right)}{\partial T}=0$ and from the above theorem the sufficient conditions are $\frac{\partial^{2} F_{4}\left(T_{1}, T\right)}{\partial T_{1}^{2}}>0$ and $\left|\begin{array}{ll}\frac{\partial^{2} F_{4}\left(T_{1}, T\right)}{\partial T_{1}^{2}} & \frac{\partial^{2} F_{4}\left(T_{1}, T\right)}{\partial T_{1} \partial T} \\ \frac{\partial^{2} F_{4}\left(T_{1}, T\right)}{\partial T_{1} \partial T} & \frac{\partial^{2} F_{4}\left(T_{1}, T\right)}{\partial T^{2}}\end{array}\right|>0$

Now $\frac{\partial Z_{4}\left(T_{1}, T\right)}{\partial T_{1}}=0$ gives

(i) $c_{2}\left\{\frac{a \alpha^{2}(2 \beta+1)}{\beta+1} T_{1}^{2 \beta}+\frac{b \alpha^{2}(2 \beta+2)}{\beta+2} T_{1}^{2 \beta+1}\right\}-c_{2} \alpha \beta T_{1}^{\beta-1}\left\{a\left(T-T_{1}\right)\right.$

$$
\left.+\frac{b}{2}\left(T^{2}-T_{1}^{2}\right)+\frac{a \alpha}{(\beta+1)} T^{\beta+1}+\frac{b \alpha}{(\beta+2)} T^{\beta+2}\right\}-c_{2}\left(a \alpha T_{1}^{\beta}+b \alpha T_{1}^{\beta+1}\right)
$$




$$
\begin{aligned}
& +c_{2} \alpha T_{1}^{\beta}\left(a+b T_{1}\right)+h\left\{+a \alpha T_{1}^{\beta+1}+\frac{b \alpha}{2} T_{1}^{\beta+2}+\frac{a \alpha^{2}}{\beta+1} T_{1}^{2 \beta+1}+\frac{b \alpha^{2}}{\beta+2} T_{1}^{2 \beta+2}\right\} \\
& +h\left\{a T_{1}+\frac{b}{2} T_{1}^{2}+\frac{a \alpha}{(\beta+1)} T_{1}^{\beta+1}+\frac{b \alpha}{(\beta+2)} T_{1}^{\beta+2}\right\}+\frac{h \alpha(\beta-1)}{\beta} T_{1}^{\beta-2}\left\{a T+\frac{b}{2} T^{2}\right. \\
& \left.+\frac{a \alpha}{(\beta+1)} T^{\beta+1}+\frac{b \alpha}{(\beta+2)} T^{\beta+2}\right\}+s\left(a+b T_{1}\right)+p I_{e}\left(a T_{1}+b T_{1}^{2}\right)=0
\end{aligned}
$$

Also, $\frac{\partial Z_{4}\left(T_{1}, T\right)}{\partial T}=0$ gives

$$
\begin{aligned}
& M-T c_{2}\left(a \alpha T^{\beta}+b \alpha T^{\beta+1}\right)\left(1-\alpha T_{1}^{\beta}\right)+T c_{2} \alpha T_{1}^{\beta}(a+b T)-h T\left\{+a \alpha T^{\beta+1}\right. \\
& \left.+\frac{b \alpha}{2} T^{\beta+2}+\frac{a \alpha^{2}}{(\beta+1)} T^{2 \beta+1}+\frac{b \alpha^{2}}{(\beta+2)} T^{2 \beta+2}\right\}+T\left\{p I_{r}+h+\frac{h \alpha(\beta-1)}{\beta} T^{\beta-2}\right\} \\
& \left\{a T+\frac{b}{2} T^{2}+\frac{a \alpha}{(\beta+1)} T^{\beta+1}+\frac{b \alpha}{(\beta+2)} T^{\beta+2}\right\}-T\left\{p I_{r}-\frac{h \alpha}{\beta}\left(T^{\beta-1}-T_{1}^{\beta-1}\right)\right\} \\
& \left\{a+b T+a \alpha T^{\beta}+b \alpha T^{\beta+1}\right\}=0
\end{aligned}
$$

Where $M$ is given by

$$
\text { (ii) } \begin{aligned}
& M=\left[k+c_{2}\left(1-\alpha T_{1}^{\beta}\right)\left\{\frac{a \alpha}{(\beta+1)} T^{\beta+1}+\frac{b \alpha}{(\beta+2)} T^{\beta+2}\right\}\right. \\
- & c_{2}\left\{\frac{a \alpha}{(\beta+1)} T_{1}^{\beta+1}+\frac{b \alpha}{(\beta+2)} T_{1}^{\beta+2}\right\}+c_{2}\left\{\frac{a \alpha^{2}}{(\beta+1)} T_{1}^{2 \beta+1}+\frac{b \alpha^{2}}{(\beta+2)} T_{1}^{2 \beta+2}\right\} \\
- & c_{2} \alpha T_{1}^{\beta}\left\{a\left(T-T_{1}\right)+\frac{b}{2}\left(T^{2}-T_{1}^{2}\right)\right\}+h\left\{\frac{a \alpha}{(\beta+2)}\left(T^{\beta+2}-T_{1}^{\beta+2}\right)\right. \\
+ & \frac{b \alpha}{2(\beta+3)}\left(T^{\beta+3}-T_{1}^{\beta+3}\right)+\frac{a \alpha^{2}}{(\beta+1)(2 \beta+2)}\left(T^{2 \beta+2}-T_{1}^{2 \beta+2}\right) \\
+ & \left.\frac{b \alpha^{2}}{(\beta+2)(2 \beta+3)}\left(T^{2 \beta+3}-T_{1}^{2 \beta+3}\right)\right\}-h\left\{\frac{a}{2}\left(T^{2}-T_{1}^{2}\right)+\frac{b}{6}\left(T^{3}-T_{1}^{3}\right)\right. \\
+ & \left.\frac{a \alpha}{(\beta+1)(\beta+2)}\left(T^{\beta+2}-T_{1}^{\beta+2}\right)+\frac{b \alpha}{(\beta+2)(\beta+3)}\left(T^{\beta+3}-T_{1}^{\beta+3}\right)\right\} \\
+ & \left\{p I_{r}-\frac{h \alpha}{\beta}\left(T^{\beta-1}-T_{1}^{\beta-1}\right)\right\}\left\{a T+\frac{b}{2} T^{2}+\frac{a \alpha}{(\beta+1)} T^{\beta+1}+\frac{b \alpha}{(\beta+2)} T^{\beta+2}\right\} \\
- & p I_{r}\left\{\frac{a}{2}\left(T^{2}-m^{2}\right)+\frac{b}{6}\left(T^{3}-m^{3}\right)+\frac{a \alpha}{(\beta+1)(\beta+2)}\left(T^{\beta+2}-m^{\beta+2}\right)\right. \\
+ & \left.s\left(a T_{1}+\frac{b}{2} T_{1}^{2}\right)+\frac{b \alpha}{(\beta+2)(\beta+3)}\left(T^{\beta+3}-m^{\beta+3}\right)\right\} \\
- & \left.p I_{e}\left\{\frac{a}{2}\left(m^{2}-T_{1}^{2}\right)+\frac{b}{3}\left(m^{3}-T_{1}^{3}\right)\right\}\right]
\end{aligned}
$$

To obtain optimal values for $T_{1}$ and $T$, we have to solve the above two equations provided they satisfy the following sufficient conditions.

Using the above theorem,

$$
\frac{\partial^{2} F_{4}\left(T_{1}, T\right)}{\partial T_{1}^{2}}>0, \text { and }\left|\begin{array}{ll}
\frac{\partial^{2} F_{4}\left(T_{1}, T\right)}{\partial T_{1}^{2}} & \frac{\partial^{2} F_{4}\left(T_{1}, T\right)}{\partial T_{1} \partial T} \\
\frac{\partial^{2} F_{4}\left(T_{1}, T\right)}{\partial T_{1} \partial T} & \frac{\partial^{2} F_{4}\left(T_{1}, T\right)}{\partial T^{2}}
\end{array}\right|>0
$$


we obtain the following results

$$
\begin{aligned}
& \text { (iii) } c_{2}\left\{\frac{a \alpha^{2} 2 \beta(2 \beta+1)}{(\beta+1)} T_{1}^{2 \beta-1}+\frac{b \alpha^{2}(2 \beta+1)(2 \beta+2)}{(\beta+2)} T_{1}^{2 \beta}\right\}-c_{2} \alpha \beta(\beta-1) T_{1}^{\beta-2} \\
& \left\{a\left(T-T_{1}\right)+\frac{b}{2}\left(T^{2}-T_{1}^{2}\right)+\frac{a \alpha}{(\beta+1)} T^{\beta+1}+\frac{b \alpha}{(\beta+2)} T^{\beta+2}\right\} \\
& +2 c_{2} \alpha \beta T_{1}^{\beta-1}\left(a+b T_{1}\right)+c_{2} b \alpha T_{1}^{\beta}+h\left\{a T+b T_{1}+a \alpha T_{1}^{\beta}+b \alpha T_{1}^{\beta+1}\right\} \\
& +\frac{h \alpha(\beta-1)(\beta-2)}{\beta} T_{1}^{\beta-3}\left\{a T+\frac{b}{2} T^{2}+\frac{a \alpha}{(\beta+1)} T^{\beta+1}+\frac{b \alpha}{(\beta+2)} T^{\beta+2}\right\} \\
& +s b+p I_{e}\left(a+2 b T_{1}\right)>h\left\{+a \alpha T_{1}^{\beta+1}+\frac{b \alpha}{2} T_{1}^{\beta+2}+\frac{a \alpha^{2}}{(\beta+1)} T_{1}^{2 \beta+1}+\frac{b \alpha^{2}}{\beta+2} T_{1}^{2 \beta+2}\right\} \\
& +c_{2}\left\{a \alpha \beta T_{1}^{\beta-1}+b \alpha(\beta+1) T_{1}^{\beta}\right\}
\end{aligned}
$$

and

$$
\begin{aligned}
& \text { (iv) }\left[c_{2}\left\{\frac{a \alpha^{2} 2 \beta(2 \beta+1)}{(\beta+1)} T_{1}^{2 \beta-1}+\frac{b \alpha^{2}(2 \beta+1)(2 \beta+2)}{(\beta+2)} T_{1}^{2 \beta}\right\}+s b+p I_{e}\left(a+2 b T_{1}\right)\right. \\
& -c_{2} \alpha \beta(\beta-1) T_{1}^{\beta-2}\left\{a\left(T-T_{1}\right)+\frac{b}{2}\left(T^{2}-T_{1}^{2}\right)+\frac{a \alpha}{(\beta+1)} T^{\beta+1}+\frac{b \alpha}{(\beta+2)} T^{\beta+2}\right\} \\
& +2 c_{2} \alpha \beta T_{1}^{\beta-1}\left(a+b T_{1}\right)+c_{2} b \alpha T_{1}^{\beta}+c_{2}\left\{a \alpha \beta T_{1}^{\beta-1}+b \alpha(\beta+1) T_{1}^{\beta}\right\} \\
& +h\left\{a T+b T_{1}+a \alpha T_{1}^{\beta}+b \alpha T_{1}^{\beta+1}\right\}+h\left\{a \alpha(\beta+1) T_{1}^{\beta}+\frac{b \alpha(\beta+2)}{2} T_{1}^{\beta+1}\right. \\
& \left.+\frac{a \alpha^{2}(2 \beta+1)}{(\beta+1)} T_{1}^{2 \beta}+\frac{b \alpha^{2}(2 \beta+2)}{\beta+2} T_{1}^{2 \beta+1}\right\}+\frac{h \alpha(\beta-1)(\beta-2)}{\beta} T_{1}^{\beta-3} \\
& \left.\left\{a T+\frac{b}{2} T^{2}+\frac{a \alpha}{(\beta+1)} T^{\beta+1}+\frac{b \alpha}{(\beta+2)} T^{\beta+2}\right\}\right]\left[c _ { 2 } \left\{a \alpha \beta T^{\beta-1}\right.\right. \\
& \left.+b \alpha(\beta+1) T^{\beta}\left(1-\alpha T_{1}^{\beta}\right)\right\}-c_{2} \alpha b T_{1}^{\beta}+\left\{p I_{r}-\frac{h \alpha}{\beta}\left(T^{\beta-1}-T_{1}^{\beta-1}\right)\right\} \\
& \left\{b+a \alpha \beta T^{\beta-1}+b \alpha(\beta+1) T^{\beta}\right\}+h \\
& \left\{a \alpha(\beta+1) T^{\beta}+\frac{b \alpha(\beta+2)}{2} T^{\beta+1}+\frac{a \alpha^{2}(2 \beta+1)}{(\beta+1)} T^{2 \beta}+\frac{b \alpha^{2}(2 \beta+2)}{\beta+2} T^{2 \beta+1}\right\} \\
& -\left\{p I_{r}+h+\frac{2 h \alpha(\beta-1)}{\beta} T^{\beta-2}\right\}\left\{a+b T+a \alpha T^{\beta}+b \alpha T^{\beta+1}\right\} \\
& \left.-\frac{h \alpha(\beta-1)(\beta-2)}{\beta} T^{\beta-3}\left\{a T+\frac{b}{2} T^{2}+\frac{a \alpha}{(\beta+1)} T^{\beta+1}+\frac{b \alpha}{(\beta+2)} T^{\beta+2}\right\}\right] \\
& >\left[c_{2} \alpha \beta T_{1}^{\beta-1}\left\{a \alpha \beta T^{\beta-1}+b \alpha(\beta+1) T^{\beta}\right\}+c_{2} b \alpha \beta T_{1}^{\beta-1}\right. \\
& \left.-\frac{h \alpha(\beta-1)}{\beta} T_{1}^{\beta-2}\left\{b+a \alpha \beta T^{\beta-1}+b \alpha(\beta+1) T^{\beta}\right\}\right]^{2}
\end{aligned}
$$




\section{Appendix 7}

Proof To minimize $Z_{5}\left(T_{1}, T\right)=\frac{1}{T} F_{5}\left(T_{1}, T\right)$, we have necessary conditions as $\frac{\partial Z_{5}\left(T_{1}, T\right)}{\partial T_{1}}=$ $0, \frac{\partial Z_{5}\left(T_{1}, T\right)}{\partial T}=0$ and from the above theorem the sufficient conditions are $\frac{\partial^{2} F_{5}\left(T_{1}, T\right)}{\partial T_{1}^{2}}>0$ and $\left|\begin{array}{ll}\frac{\partial^{2} F_{5}\left(T_{1}, T\right)}{\partial T_{1}^{2}} & \frac{\partial^{2} F_{5}\left(T_{1}, T\right)}{\partial T_{1} \partial T} \\ \frac{\partial^{2} F_{5}\left(T_{1}, T\right)}{\partial T_{1} \partial T} & \frac{\partial^{2} F_{5}\left(T_{1}, T\right)}{\partial T^{2}}\end{array}\right|>0$

Now $\frac{\partial Z_{5}\left(T_{1}, T\right)}{\partial T_{1}}=0$ gives

$$
\begin{aligned}
& \text { (i) } c_{2}\left\{\frac{a \alpha^{2}(2 \beta+1)}{\beta+1} T_{1}^{2 \beta}+\frac{b \alpha^{2}(2 \beta+2)}{\beta+2} T_{1}^{2 \beta+1}\right\}-c_{2} \alpha \beta T_{1}^{\beta-1}\left\{a\left(T-T_{1}\right)+\frac{b}{2}\left(T^{2}-T_{1}^{2}\right)\right. \\
& \left.+\frac{a \alpha}{(\beta+1)} T^{\beta+1} \frac{b \alpha}{(\beta+2)} T^{\beta+2}\right\}-c_{2}\left(a \alpha T_{1}^{\beta}+b \alpha T_{1}^{\beta+1}\right)+c_{2} \alpha T_{1}^{\beta}\left(a+b T_{1}\right) \\
& +h\left\{+a \alpha T_{1}^{\beta+1}+\frac{b \alpha}{2} T_{1}^{\beta+2}+\frac{a \alpha^{2}}{\beta+1} T_{1}^{2 \beta+1}+\frac{b \alpha^{2}}{\beta+2} T_{1}^{2 \beta+2}\right\} \\
& +h\left\{a T_{1}+\frac{b}{2} T_{1}^{2}+\frac{a \alpha}{(\beta+1)} T_{1}^{\beta+1}+\frac{b \alpha}{(\beta+2)} T_{1}^{\beta+2}\right\}+\frac{h \alpha(\beta-1)}{\beta} T_{1}^{\beta-2} \\
& \left\{a T+\frac{b}{2} T^{2}+\frac{a \alpha}{(\beta+1)} T^{\beta+1}+\frac{b \alpha}{(\beta+2)} T^{\beta+2}\right\}+s\left(a+b T_{1}\right) \\
& +p I_{e}\left(a T_{1}+b T_{1}^{2}\right)+p I_{e}(m-T)\left(a+b T_{1}\right)=0
\end{aligned}
$$

Also, $\frac{\partial Z_{5}\left(T_{1}, T\right)}{\partial T}=0$ gives

(ii) $P-T c_{2}\left(a \alpha T^{\beta}+b \alpha T^{\beta+1}\right)\left(1-\alpha T_{1}^{\beta}\right)+T c_{2} \alpha T_{1}^{\beta}(a+b T)-h T\left\{+a \alpha T^{\beta+1}\right.$

$$
\begin{aligned}
& \left.+\frac{b \alpha}{2} T^{\beta+2}+\frac{a \alpha^{2}}{(\beta+1)} T^{2 \beta+1}+\frac{b \alpha^{2}}{(\beta+2)} T^{2 \beta+2}\right\}+T\left\{h+\frac{h \alpha(\beta-1)}{\beta} T^{\beta-2}\right\} \\
& \left\{a T+\frac{b}{2} T^{2}+\frac{a \alpha}{(\beta+1)} T^{\beta+1}+\frac{b \alpha}{(\beta+2)} T^{\beta+2}\right\}+p I_{e}\left(a T+b T^{2}\right) \\
& +\frac{h \alpha}{\beta}\left(T^{\beta-1}-T_{1}^{\beta-1}\right)\left\{a+b T+a \alpha T^{\beta}+b \alpha T^{\beta+1}\right\}-p I_{e}\left\{a\left(T-T_{1}\right)+\frac{b}{2}\left(T^{2}-T_{1}^{2}\right)\right\} \\
& +p I_{e}(m-T)(a+b T)=0
\end{aligned}
$$

Where $P$ is given by

$$
\begin{aligned}
P=[k & +c_{2}\left(1-\alpha T_{1}^{\beta}\right)\left\{\frac{a \alpha}{(\beta+1)} T^{\beta+1}+\frac{b \alpha}{(\beta+2)} T^{\beta+2}\right\}-c_{2}\left\{\frac{a \alpha}{(\beta+1)} T_{1}^{\beta+1}\right. \\
& \left.+\frac{b \alpha}{(\beta+2)} T_{1}^{\beta+2}\right\}+c_{2}\left\{\frac{a \alpha^{2}}{(\beta+1)} T_{1}^{2 \beta+1}+\frac{b \alpha^{2}}{(\beta+2)} T_{1}^{2 \beta+2}\right\}-c_{2} \alpha T_{1}^{\beta}\left\{a\left(T-T_{1}\right)\right. \\
& \left.+\frac{b}{2}\left(T^{2}-T_{1}^{2}\right)\right\}+h\left\{\frac{a \alpha}{(\beta+2)}\left(T^{\beta+2}-T_{1}^{\beta+2}\right)+\frac{b \alpha}{2(\beta+3)}\left(T^{\beta+3}-T_{1}^{\beta+3}\right)\right. \\
& \left.+\frac{a \alpha^{2}}{(\beta+1)(2 \beta+2)}\left(T^{2 \beta+2}-T_{1}^{2 \beta+2}\right)+\frac{b \alpha^{2}}{(\beta+2)(2 \beta+3)}\left(T^{2 \beta+3}-T_{1}^{2 \beta+3}\right)\right\} \\
& -h\left\{\frac{a}{2}\left(T^{2}-T_{1}^{2}\right)+\frac{b}{6}\left(T^{3}-T_{1}^{3}\right)+\frac{a \alpha}{(\beta+1)(\beta+2)}\left(T^{\beta+2}-T_{1}^{\beta+2}\right)\right.
\end{aligned}
$$




$$
\begin{aligned}
& \left.+\frac{b \alpha}{(\beta+2)(\beta+3)}\left(T^{\beta+3}-T_{1}^{\beta+3}\right)\right\}-\frac{h \alpha}{\beta}\left(T^{\beta-1}-T_{1}^{\beta-1}\right)\left\{a T+\frac{b}{2} T^{2}\right. \\
& \left.+\frac{a \alpha}{(\beta+1)} T^{\beta+1}+\frac{b \alpha}{(\beta+2)} T^{\beta+2}\right\}+s\left(a T_{1}+\frac{b}{2} T_{1}^{2}\right)-p I_{e}\left\{\frac{a}{2}\left(T^{2}-T_{1}^{2}\right)\right. \\
& \left.\left.+\frac{b}{3}\left(T^{3}-T_{1}^{3}\right)\right\}-p I_{e}(m-T)\left\{a\left(T-T_{1}\right)+\frac{b}{2}\left(T^{2}-T_{1}^{2}\right)\right\}\right]
\end{aligned}
$$

To obtain optimal values for $T_{1}$ and $T$, we have to solve the above two equations provided they satisfy the following sufficient conditions.

Using the above theorem,

$$
\frac{\partial^{2} F_{5}\left(T_{1}, T\right)}{\partial T_{1}^{2}}>0, \text { and }\left|\begin{array}{ll}
\frac{\partial^{2} F_{5}\left(T_{1}, T\right)}{\partial T_{1}^{2}} & \frac{\partial^{2} F_{5}\left(T_{1}, T\right)}{\partial T_{1} \partial T} \\
\frac{\partial^{2} F_{5}\left(T_{1}, T\right)}{\partial T_{1} \partial T} & \frac{\partial^{2} F_{5}\left(T_{1}, T\right)}{\partial T^{2}}
\end{array}\right|>0
$$

we obtain the following results

$$
\begin{aligned}
& \text { (iii) } c_{2}\left\{\frac{a \alpha^{2} 2 \beta(2 \beta+1)}{(\beta+1)} T_{1}^{2 \beta-1}+\frac{b \alpha^{2}(2 \beta+1)(2 \beta+2)}{(\beta+2)} T_{1}^{2 \beta}\right\} \\
& -c_{2} \alpha \beta(\beta-1) T_{1}^{\beta-2}\left\{a\left(T-T_{1}\right)+\frac{b}{2}\left(T^{2}-T_{1}^{2}\right)+\frac{a \alpha}{(\beta+1)} T^{\beta+1}+\frac{b \alpha}{(\beta+2)} T^{\beta+2}\right\} \\
& +2 c_{2} \alpha \beta T_{1}^{\beta-1}\left(a+b T_{1}\right)+c_{2} b \alpha T_{1}^{\beta}+h\left\{a T+b T_{1}+a \alpha T_{1}^{\beta}+b \alpha T_{1}^{\beta+1}\right\} \\
& +\frac{h \alpha(\beta-1)(\beta-2)}{\beta} T_{1}^{\beta-3}\left\{a T+\frac{b}{2} T^{2}+\frac{a \alpha}{(\beta+1)} T^{\beta+1}+\frac{b \alpha}{(\beta+2)} T^{\beta+2}\right\}+s b \\
& +p I_{e}\left(a+2 b T_{1}\right)+p b(m-T) I_{e}>h\left\{a \alpha(\beta+1) T_{1}^{\beta}+\frac{b \alpha(\beta+2)}{2} T_{1}^{\beta+1}\right. \\
& \left.+\frac{a \alpha^{2}(2 \beta+1)}{(\beta+1)} T_{1}^{2 \beta}+\frac{b \alpha^{2}(2 \beta+2)}{\beta+2} T_{1}^{2 \beta+1}\right\}+c_{2}\left\{a \alpha \beta T_{1}^{\beta-1}+b \alpha(\beta+1) T_{1}^{\beta}\right\}
\end{aligned}
$$

and

$$
\begin{aligned}
& \text { (iv) }\left[c_{2}\left\{\frac{a \alpha^{2} 2 \beta(2 \beta+1)}{(\beta+1)} T_{1}^{2 \beta-1}+\frac{b \alpha^{2}(2 \beta+1)(2 \beta+2)}{(\beta+2)} T_{1}^{2 \beta}\right\}+s b+p I_{e}\left(a+2 b T_{1}\right)\right. \\
& +p b(m-T) I_{e}-c_{2} \alpha \beta(\beta-1) T_{1}^{\beta-2}\left\{a\left(T-T_{1}\right)+\frac{b}{2}\left(T^{2}-T_{1}^{2}\right)+\frac{a \alpha}{(\beta+1)} T^{\beta+1}\right. \\
& \left.+\frac{b \alpha}{(\beta+2)} T^{\beta+2}\right\}+2 c_{2} \alpha \beta T_{1}^{\beta-1}\left(a+b T_{1}\right)+c_{2} b \alpha T_{1}^{\beta}+c_{2}\left\{a \alpha \beta T_{1}^{\beta-1}+b \alpha(\beta+1) T_{1}^{\beta}\right\} \\
& -\frac{h \alpha}{\beta}\left(T^{\beta-1}-T_{1}^{\beta-1}\right)\left\{b+a \alpha \beta T^{\beta-1}+b \alpha(\beta+1) T^{\beta}\right\}+h\left\{a T+b T_{1}+a \alpha T_{1}^{\beta}+b \alpha T_{1}^{\beta+1}\right\} \\
& +h\left\{a \alpha(\beta+1) T_{1}^{\beta}+\frac{b \alpha(\beta+2)}{2} T_{1}^{\beta+1}+\frac{a \alpha^{2}(2 \beta+1)}{(\beta+1)} T_{1}^{2 \beta}+\frac{b \alpha^{2}(2 \beta+2)}{\beta+2} T_{1}^{2 \beta+1}\right\} \\
& \left.+\frac{h \alpha(\beta-1)(\beta-2)}{\beta} T_{1}^{\beta-3}\left\{a T+\frac{b}{2} T^{2}+\frac{a \alpha}{(\beta+1)} T^{\beta+1}+\frac{b \alpha}{(\beta+2)} T^{\beta+2}\right\}\right] \\
& {\left[c_{2}\left\{a \alpha \beta T^{\beta-1}+b \alpha(\beta+1) T^{\beta}\right\}\left(1-\alpha T_{1}^{\beta}\right)-c_{2} \alpha b T_{1}^{\beta}+h\left\{a \alpha(\beta+1) T^{\beta}\right.\right.} \\
& \left.+\frac{b \alpha(\beta+2)}{2} T^{\beta+1}+\frac{a \alpha^{2}(2 \beta+1)}{(\beta+1)} T^{2 \beta}+\frac{b \alpha^{2}(2 \beta+2)}{\beta+2} T^{2 \beta+1}\right\}-\left\{h+\frac{2 h \alpha(\beta-1)}{\beta} T^{\beta-2}\right\} \\
& \left\{a+b T+a \alpha T^{\beta}+b \alpha T^{\beta+1}\right\}-p I_{e}(a+2 b T)-p b I_{e}(m-T)+2 p I_{e}(a+b T)
\end{aligned}
$$




$$
\begin{aligned}
& \left.-\frac{h \alpha(\beta-1)(\beta-2)}{\beta} T^{\beta-3}\left\{a T+\frac{b}{2} T^{2}+\frac{a \alpha}{(\beta+1)} T^{\beta+1}+\frac{b \alpha}{(\beta+2)} T^{\beta+2}\right\}\right] \\
& >\left[\frac{h \alpha(\beta-1)}{\beta} T_{1}^{\beta-2}\left\{b+a \alpha \beta T^{\beta-1}+b \alpha(\beta+1) T^{\beta}\right\}\right. \\
& \left.-c_{2} \alpha \beta T_{1}^{\beta-1}\left\{a \alpha \beta T^{\beta-1}+b \alpha(\beta+1) T^{\beta}\right\}-c_{2} b \alpha \beta T_{1}^{\beta-1}\right]^{2}
\end{aligned}
$$

\section{References}

1. Silver, E.A., Meal, H.C.: A simple modification of the EOQ for the case of a varying demand rate. Prod. Inventory Manag. 10, 52-65 (1969)

2. Donaldson, W.A.: Inventory replenishment policy for a linear trend in demand-an analytical solution. Oper. Res. Q. 28, 663-670 (1977)

3. Deb, M., Chaudhuri, K.S.: A note on the heuristic for replenishment of trended inventories considering shortages. J. Oper. Res. Soc. 38, 459-463 (1987)

4. Ghare, P.M., Schrader, G.F.: An inventory model for exponentially deteriorating items. J. Ind. Eng. 14, 238-243 (1963)

5. Covert, R.P., Philip, G.C.: An EOQ model for items with Weibull distribution deterioration. AIIE Trans. 5, 323-326 (1973)

6. Sarkar, B., Sarkar, S.: An improved inventory model with partial backlogging, time varying deterioration and stock-dependent demand. Econ. Model. 30, 924-932 (2013)

7. Sarkar, B., Sarkar, S.: Variable deterioration and demand-an inventory model. Econ. Model. 31, 548-556 (2013)

8. Philip, G.C.: A generalized EOQ model for items with Weibull distribution deterioration. AIIE Trans. 6, 159-162 (1974)

9. Shah, Y.K.: An order-level lot-size inventory model for deteriorating items. AIIE Trans. 9, 108-112 (1977)

10. Goyal, S.K., Marin, D., Nebebe, F.: The finite horizon trended inventory replenishment problem with shortages. J. Oper. Res. Soc. 43, 1173-1178 (1992)

11. Goswami, A., Chaudhuri, K.S.: An EOQ model for deteriorating items with a linear trend in demand. J. Oper. Res. Soc. 42, 1105-1110 (1991)

12. Hariga, M.: Optimal EOQ models for deteriorating items with time-varying demand. J. Oper. Res. Soc. 47, 1228-1246 (1996)

13. Ouyang, L.Y., Wu, K.S., Yang, C.T.: A study on an inventory model for non- instantaneous deteriorating items with permissible delay in payments. Comput. Ind. Eng. 51, 637-651 (2006)

14. Goyal, S.K., Cárdenas-Barrón, L.E.: Note on: economic production quantity model for items with imperfect quality - a practical approach. Int. J. Prod. Econ. 77, 85-87 (2003)

15. Sarkar, B., Saren, S., Cárdenas-Barrón, L.E.: An inventory model with trade-credit policy and variable deterioration for fixed lifetime products. Ann. Oper. Res. (2014). doi:10.1007/s10479-014-1745-9

16. Goyal, S.K.: EOQ under conditions of permissible delay in payments. J. Oper. Res. Soc. 36, 335-338 (1985)

17. Aggarwal, S.P., Jaggi, C.K.: Ordering policies of deteriorating items under permissible delay in payments. J. Oper. Res. Soc. 36, 658-662 (1995)

18. Sarkar, B.: An EOQ model with delay in payment and time varying deterioration rate. Math. Comput. Model. 55, 367-377 (2012b)

19. Chung, K.J., Cárdenas-Barrón, L.E.: The simplified solution procedure for deteriorating items under stock-dependent demand and two-level trade credit in the supply chain management. Appl. Math. Model. 37(7), 4653-4660 (2013)

20. Pal, B., Sana, S.S., Chaudhuri, K.S.: Three stage trade credit policy in a three-layer supply chain-a production-inventory model. Int. J. Syst. Sci. 45, 1844-1868 (2012)

21. Chung, K.J., Huang, C.K.: An ordering policy with allowable shortage and permissible delay in payments. Appl. Math. Model. 33, 2518-2525 (2009)

22. Pal, B., Sana, S.S., Chaudhuri, K.K.: Two-echelon competitive integrated supply chain model with price and credit period dependent demand. Int. J. Syst. Sci. (2014). doi:10.1080/00207721.2014.911383

23. Mahata, G.C.: EOQ model for items with exponential distribution deterioration and linear trend demand under permissible delay in payments. Int. J. Soft. Comput. 6(3), 46-53 (2011)

24. Singh, T., Pattnayak, H.: An EOQ model for deteriorating item with time dependent quadratic demand and variable deterioration under permissible delay in payment. Appl. Math. Sci. 7, 2939-2951 (2013) 
25. Singh, S., Singh, S.: An optimal inventory policy for items having linear demand and variable deterioration rate with trade credit. J. Math. Stat. 5(4), 330-333 (2009)

26. Amutha, R., Chandrasekaran, E.: An inventory model for constant demand with shortages under permissible delay in payments. IOSR J. Math. 6, 28-33 (2013)

27. Anand, Bansal, K.K.: Modelling of an inventory system for decaying items with time dependent demand rate under permissible delay. Int. J. Adv. Res. Comput. Sci. Softw. Eng. 3, 5 (2013)

28. Sarkar, M., Sarkar, B.: An economic manufacturing quantity model with probabilistic deterioration in a production system. Econ. Model. 31, 245-252 (2013)

29. Sarkar, B., Saren, S., Wee, H.M.: An inventory model with variable demand, component cost and selling price for deteriorating items. Econ. Model. 30, 306-310 (2013)

30. Sarkar, B., Saren, S.: Partial trade-credit policy of retailer with exponentially deteriorating items. Int. J. Appl. Comput. Math. (2014). doi:10.1007/s40819-014-0019-1

31. Sana, S.S., Chaudhuri, K.S.: A deterministic EOQ model with delays in payments and price discount offers. Eur. J. Oper. Res. 184, 509-533 (2008)

32. Ouyang, L.Y., Yang, C.T., Chan, Y.L., Ca'rdenas-Barro'n, L.E.: A comprehensive extension of the optimal replenishment decisions under two levels of trade credit policy depending on the order quantity. Appl. Math. Comput. 224(1), 268-277 (2013)

33. Sana, S.S.: Optimal selling price and lot size with time varying deterioration and partial backlogging. Appl. Math. Comput. 217, 185-194 (2010)

34. Khanra, S., Ghosh, S.K., Chaudhuri, K.S.: An EOQ model for a deteriorating items with time dependent quadratic demand under permissible delay in payment. Appl. Math. Comput. 218, 1-9 (2011)

35. Khanra, S., Mandal, B., Sarkar, B.: An inventory model with time dependent demand and shortages under trade credit policy. Econ. Model. 35, 349-355 (2013)

36. Das Roy, M., Sana, S.S., Chaudhuri, K.S.: An economic order quantity model of imperfect quality items with partial backlogging. Int. J. Syst. Sci. 42, 1409-1419 (2011)

37. Sarkar, B.: An EOQ model with delay in payment and stock dependent demand in the present of imperfect product. Appl. Math. Comput. 218, 8295-8308 (2012a)

38. Sarkar, B.: A production-inventory model with probabilistic deterioration in two-echelon supply chain management. Appl. Math. Model. 37, 3138-3151 (2013)

39. Sarkar, B., Sana, S.S., Chaudhuri, K.S.: An inventory model with finite replenishment rate, trade credit policy and price-discount offer. J. Ind. Eng. (2013). doi:10.1155/2013/672504

40. Wu, J., Ouyang, L.Y., Cárdenas-Barrón, L.E., Goyal, S.K.: Optimal credit period and lot size for deteriorating items with expiration dates under two-level trade credit financing. Eur. J. Oper. Res. 237(3), 898-908 (2014)

41. Chung, K.J., Cárdenas-Barrón, L.E., Ting, P.S.: An inventory model with non-instantaneous receipt and exponentially deteriorating items for an integrated three layer supply chain system under two levels of trade credit. Int. J. Prod. Econ. 155, 310-317 (2014)

42. Chen, S.-H., Cárdenas-Barrón, L.E., Teng, J.T.: Retailer's economic order quantity when the supplier offers conditionally permissible delay in payments link to order quantity. Int. J. Prod. Econ. 155, 284-291 (2014)

43. Sarkar, B., Cárdenas-Barrón, L.E., Sarkar, M., Singgih, M.L.: An economic production quantity model with random defective rate, rework process and backorders for a single stage production system. J. Manuf. Syst. 33(3), 423-435 (2014)

44. Sarkar, B., Moon, I.: Improved quality, setup cost reduction, and variable backorder costs in an imperfect production process. Int. J. Prod. Econ. 155, 204-213 (2014)

45. Sarkar, B., Gupta, H., Chaudhuri, K.S., Goyal, S.K.: An integrated inventory model with variable lead time, defective units and delay in payments. Appl. Math. Comput. 237, 650-658 (2014)

46. Sarkar, B., Mandal, B., Sarkar, S.: Quality improvement and backorder price discount under controllable lead time in an inventory model. J. Manuf. Syst. 35, 26-36 (2015) 